Augusto Mathias

Comportamento de risco de transmissão do HIV e uso de drogas psicoativas em uma população de homens que fazem sexo com homens

Dissertação apresentada à Faculdade de Medicina da Universidade de São Paulo para obtenção do titulo de Mestre em Ciências

Programa de Medicina Preventiva

Orientador: Prof.Dr. Heráclito Barbosa de Carvalho

São Paulo

2014 
Augusto Mathias

Comportamento de risco de transmissão do HIV e uso de drogas psicoativas em uma população de homens que fazem sexo com homens

Dissertação apresentada à Faculdade de Medicina da Universidade de São Paulo para obtenção do titulo de Mestre em Ciências

Programa de Medicina Preventiva

Orientador: Prof.Dr. Heráclito Barbosa de Carvalho

São Paulo

2014 
Dados Internacionais de Catalogação na Publicação (CIP)

Preparada pela Biblioteca da

Faculdade de Medicina da Universidade de São Paulo

Creprodução autorizada pelo autor

\section{Mathias, Augusto}

Comportamento de risco de transmissão do HIV e uso de drogas psicoativas em uma população de homens que fazem sexo com homens / Augusto Mathias. São Paulo, 2014.

Dissertação(mestrado)--Faculdade de Medicina da Universidade de São Paulo. Programa de Medicina Preventiva.

Orientador: Heráclito Barbosa de Carvalho.

Descritores: 1.Vulnerabilidade em saúde 2. Homossexualidade masculina 3.HIV 4.Psicoativos

USP/FM/DBD-187/14 
Índice

$\begin{array}{ll}\text { Introdução } & 1\end{array}$

$\begin{array}{ll}\text { Justificativa } & 13\end{array}$

$\begin{array}{ll}\text { Objetivos Gerais } & 14\end{array}$

$\begin{array}{ll}\text { Objetivos Específicos } & 14\end{array}$

$\begin{array}{ll}\text { Método } & 15\end{array}$

$\begin{array}{ll}\text { Instrumentos } & 15\end{array}$

$\begin{array}{ll}\text { Amostra } & 19\end{array}$

$\begin{array}{ll}\text { Entrevistas } & 19\end{array}$

$\begin{array}{ll}\text { Coleta de dados e Análises Estatísticas } & 20\end{array}$

$\begin{array}{ll}\text { Análise Qualitativa } & 20\end{array}$

Considerações Éticas $\quad 22$ 
Resultados

Resultados qualitativos

Discussão

Conclusão

58

Considerações Finais

Anexos

60

Referências Bibliográficas 


\section{Agradecimentos}

Agradeço à CAPES pelo fomento da bolsa que me permitiu realizar este trabalho.

Agradeço ao Prof. Heráclito Barbosa de Carvalho por abrir a porta do Departamento de Medicina Preventiva da Universidade de São Paulo.

Meu muito obrigado aos voluntários desse estudo. Sem vocês, nada disso seria possível.

Agradeço à Lilian e à Gorete, secretárias do Departamento de Medicina Preventiva, que ajudaram com todos os processos burocráticos.

Obrigado aos amigos que iniciaram essa jornada comigo e aos que conheci durante o caminho. Mas, especialmente, tenho que agradecer à Ana Lucia Spiassi pela grande ajuda em momentos de total confusão e loucura, e à Márcia Cunha, por me apoiar em momentos muito difíceis e me ajudando a tomar uma das decisões mais importantes de todo esse processo.

Não posso esquecer dos amigos que sempre estiveram a postos com seus ouvidos para receber minhas lamúrias e desventuras. Desses, quero deixar um obrigado especial para Camila Monteiro, Grace Noronha, Gina Orsório, Juliana Kodaira, Barbara Moura, Bruna Demari, Liza Uchimura e Andréa Tenório. Meu muito obrigado.

Obrigado a minha família que, mesmo a distância, sempre se orgulharou e me apoiou em todos os meus estudos. 
Ao meu marido, Ricardo Palacios, quero fazer um agradecimento especial. $\mathrm{Na}$ verdade, não sei como transformar em palavras o que gostaria de dizer. Tenho que agradecer não só pela vida compartilhada, mas pela ajuda em todos os momentos deste trabalho; nas comemorações, nos choros, nas crises, nas evoluções e revoluções. Obrigado pelo apoio e pelo amor incondicional. Te amo. 


\section{Resumo}

Comportamento de risco de transmissão do HIV em uma população de homens que fazem sexo com homens e drogas psicoativas

Diversos estudos apontam que existe maior vulnerabilidade - em suas três dimensões, individual, social e programática - para aquisição de HIV em homens que fazem sexo com homens $(\mathrm{HSH})$, e essa vulnerabilidade se potencializa quando avaliada em condições relacionadas ao uso de drogas psicoativas. Esse estudo explorou a relação entre o uso recreativo de droga psicoativa e sexo em população de HSH. Participaram da pesquisa 34 sujeitos selecionados em uma amostra de conveniência, os quais responderam questionário estruturado e semiestruturado sobre o uso de drogas e o comportamento sexual. O tamanho da amostra foi definido com base na técnica qualitativa de esgotamento de discurso. Foi utilizada análise descritiva para as questões quantitativas e análise de conteúdo para as questões qualitativas. Dos participantes, 91\% (31) referiram uso drogas psicoativas. O álcool foi relatado por $94 \%$ (29) dos indivíduos, sendo o mais frequente entre as drogas licitas. A maconha, entre as drogas ilícitas, foi relatada por $58 \%$ (18). O uso intermitente do preservativo apareceu em $91 \%$ (31) das respostas. A mediana relatada de parceiros sexuais no mês anterior à pesquisa foi de $1,5\left(\mathrm{P}_{25-75: 1-4)}\right.$. $\mathrm{A}$ análise de conteúdo mostrou uma percepção conservadora sobre a relação entre uso de drogas e sexo. 0 preservativo foi citado como a forma mais conhecida de prevenção. A 
utilização de drogas não pareceu ser o fator mais relevante associado às falhas relacionadas ao uso de estratégias de prevenção. O estudo mostrou que outros fatores, como capacidade de negociação com o parceiro, realizar oportunidades baseadas no risco e principalmente o desejo sexual, podem influenciar mais no não uso de preservativo do que as drogas psicoativas. Apesar de ter sido observada uma associação entre o uso de drogas psicoativas e a falha de prevenção no comportamento sexual de risco, fica evidente a necessidade de maior compreensão das variáveis envolvidas nesse processo para tornar mais efetivas as ações programáticas de prevenção de HIV e outras DSTs nessa população.

Descritores: 1.Vulnerabilidade em saúde, 2.Homossexualidade masculina, 3.HIV, 4.Psicoativos 


\begin{abstract}
Behavior transition HIV risk in in men who have sex with men population and psychoactive drugs
\end{abstract}

Several studies pointed out higher vulnerability for HIV acquisition; in terms of individual, social and programmatic dimensions; in men who have sex with men (MSM). This vulnerability appears to be enhanced when assessed on psychoactive drug use conditions. This study explored the relationship between recreational use of psychoactive drugs and sex in the MSM population. Thirty-four individuals selected by convenience sample participated in the study. They answered structured and semi-structured questionnaires on drug use and sexual behavior. The sample size was defined on qualitative technique, up to the number when data saturation was achieved. Descriptive analysis was used for quantitative questions and content analysis for qualitative answers. The results showed that $91 \%$ (31) of the group referred psychoactive drug use. The most frequent licit drug used was alcohol 94\% (29) and for illicit drug was marijuana 58\% (18). The intermittent condom use was reported by $91 \%$ of them. The median reported number of sexual partners in the last month in this group was $1.5\left(\mathrm{P}_{25-75}\right.$ : 1 4). The content analysis showed a conservative perception toward drug use and sex relationship. The condom appeared as the best-known prevention form. The use of drugs did not appear to be the most significant factor associated with prevention strategies failures. The study showed that other factors; such as ability to negotiate with the partner, taking risk-based 
opportunities and, particularly, sex drive; might have higher influence in dismissing condom use than psychoactive drugs use. Despite an association between use of psychoactive drugs and failure to avoid sexual risk behavior was observed, a better understanding of variables involved in this process is needed to make programmatic actions to prevent HIV and other STIs more effective in this population.

Descriptions: 1. Health vulnerability, 2. Male homosexuality, 3. HIV, 4. Psychoactives 


\section{Introdução}

Historicamente, o uso das drogas psicoativas é objeto de estudo na área da saúde, podendo ser um indicador importante para estudar risco em grupos específicos, e mesmo para a população em geral. Domanico (2006) faz ampla retomada histórica sobre o uso de drogas, principalmente a cocaína e o crack. A autora nos lembra de que o aperfeiçoamento da química no século XIX permitiu aos cientistas isolar inúmeros princípios ativos de plantas psicoativas, possibilitando, dessa maneira, o desenvolvimento de novas drogas, como a morfina (1803), a heroína (1859) e a própria cocaína (1859). Domanico informa ainda que, em 1883, a cocaína era "testada no exército alemão como estimulante para soldados nos campos de batalha". Também considera que seu uso influenciou importantes nomes da ciência, como psiquiatra Sigmund Freud, considerado pai da psicanálise moderna, o qual ponderava que a cocaína era um ótimo remédio para patologias como tuberculose ou abstinência de álcool, dentre outras.

Várias drogas surgiram nessa perspectiva de uso terapêutico, podendo ser citados nessa categoria o êxtase (MDMA, 3,4metilenodioximetanfetamina), o qual surgiu como moderador de apetite, sendo, depois, usado como facilitador em processos terapêuticos (Almeida; Silva, 2000), e os opióides, como a morfina, usados como anestésicos, mas também de forma recreativa, devido aos efeitos de analgesia (Duarte, 2005; 
OBID, 2011).

No entanto, quando abordamos a questão contemporânea das drogas psicoativas, vemos que o uso recreativo se concentra na juventude, como mostrado no $V$ Levantamento Nacional sobre o Consumo de Drogas Psicotrópicas entre Estudantes do Ensino Fundamental e Médio da Rede Pública de Ensino nas 27 Capitais Brasileiras, produzido pelo Centro Brasileiro de Informações sobre Drogas Psicotrópicas (CEBRID, 2004), segundo o qual há início precoce dessa prática, usualmente com o consumo de álcool. Resultado semelhante é apresentado no I Levantamento Nacional sobre os Padrões de Consumo de Álcool na População Brasileira, com identificação do consumo regular desta droga na faixa etária de 18 a 25 anos (Laranjeira, 2007), sendo esta faixa etária caracteristicamente usuária também de drogas ilícitas. Segundo a United Nations Office on Drugs and Crime (UNODC), isso se dá de forma mais clara entre os jovens do sexo masculino que vivem em ambientes urbanos, onde, desde a metade do século $X X$, tem sido observado um número crescente de substâncias psicoativas e aumento nas chances de contato desses jovens com as drogas (UNODC, 2012)

O contexto atual do uso de drogas no mundo e em nosso país pode ser entendido no Relatório Mundial sobre Drogas da UNODC (UNDOC, 2012). No cenário mundial, o relatório de 2012 coloca que ao menos 5\% da população adulta já fez uso de drogas uma vez ou mais, e que as drogas são um importante fator para a transmissão HIV, entre outras consequências 
sociais (UNODC, 2012).

Nesse trabalho, entendemos como droga ilícita toda substância que tenha sua comercialização proibida por lei, sem considerar possíveis finalidades terapêuticas que, por ventura, uma substância possa ter.

Temos muitas drogas psicoativas no mercado. Muitas estão regulamentadas e distribuídas conforme a lei. Entretanto, não priorizamos o uso de drogas psicoativas legais nesse estudo, com a exceção do álcool e do tabaco. Nossa proposta é entender o uso das drogas psicoativas ilícitas na população do estudo.

No Brasil, drogas psicoativas "são aquelas que atuam sobre o cérebro, alterando de alguma forma o psiquismo", segundo o Observatório Brasileiro de Informações sobre Drogas (OBID, 2011). As drogas psicoativas estão classificadas em três grupos: depressoras, estimulantes e perturbadoras.

Nos grupos de drogas depressoras do sistema nervoso central, temos o álcool, barbitúricos, benzodiazepínicos, inalantes e opiáceos. No grupo das drogas estimulantes do sistema nervoso central são colocadas as anfetaminas, cocaína e tabaco. Entre as drogas que compõem o grupo das perturbadoras do sistema nervoso central, temos a maconha, os alucinógenos, o LSD, o êxtase e os anticolinérgicos.

O OBID faz uma ressalva de que "nem todas as substâncias psicoativas têm a capacidade de provocar dependência. Muitas são usadas 
com a finalidade de produzir efeitos benéficos no tratamento de doenças, sendo consideradas como medicamentos neste caso." (OBID, 2011).

Visualizando o cenário das drogas psicoativas e como elas se distribuem na população da América do Sul, vemos que, em 2008, estimouse que 1,3 milhão a 1,8 milhão de pessoas (prevalência anual de $0,5 \%$ a 0,7\%) usaram substâncias ilícitas do grupo das anfetaminas (UNODC, 2010).

No Brasil, segundo o I Levantamento Domiciliar de Drogas Psicoativas, em 2001, 19,4\% da população fizeram uso, ao menos uma vez na vida, de algum tipo de droga que não fosse tabaco e álcool (CEBRID, 2001). Em 2005, tivemos um aumento de 3,4\% nesse consumo. Buscando um recorte por região, cerca de $24,5 \%$ da população do Sudeste já experimentaram, algum tipo de droga que não fosse tabaco e álcool ao menos uma vez na vida, enquanto a porcentagem nacional estava em $22,8 \%$ no mesmo período. Estes estudos também demonstraram um maior uso por parte dos indivíduos do sexo masculino em relação aos do sexo feminino (CEBRID, 2005).

Em vista do cenário que buscamos apresentar acima, o MDMA (3,4metilenodioximetanfetamina), comumente chamado de êxtase, surgiu na Alemanha entre os anos 1912 e 1914. Foi testado inicialmente como moderador de apetite, mas nunca foi comercializado e foi muito pouco utilizado, devido a seus inúmeros efeitos colaterais. Em 1965, Alexander Shulgin retomou a pesquisa sobre MDMA e, no inicio dos anos 1970 , tomou conhecimento de outros pesquisadores muito entusiasmados com o uso 
terapêutico do MDMA. Como também citado por Almeida e Silva (2000), a comunidade científica só veio a ser formalmente informada sobre o MDMA em 1978, por meio de uma publicação de Shulgin e Nichols, a qual sugere que a droga poderia ser utilizada como auxiliar psicoterapêutico para depressão e desordem depressiva pós-traumática (Almeida e Silva, 2000)

Battisti (2006) descreve que somente na década de 1980 o êxtase passou a ser usado como droga recreativa. No Brasil, o uso começou cerca de 10 anos depois, em lugares específicos e por grupos bem caracterizados, os quais foram se modificando com o passar do tempo. Em meados da década de 1990, seus usuários eram caracterizados como frequentadores dos chamados inferninhos ${ }^{1}$, casas noturnas e bares.

No final da década de 1990, os usuários começaram a sair desses locais mais undreground ${ }^{2}$ para festas ao ar livre chamadas Raves ${ }^{3}$. Battisti informa ainda que esses sujeitos eram caracterizados como jovens e jovens adultos, pertencentes à classe média ou média alta, tendo grande porcentagem de população com ensino superior (Battisti et al., 2006)

O II Levantamento Domiciliar sobre o Uso de Drogas Psicoativas (CEBRID, 2005), mais recente documento disponível que avalia em grande escala a magnitude da questão no nível nacional, informa sobre a extensão da questão, com $22,8 \%$ dos participantes tendo feito uso de alguma droga ao menos uma vez na vida. O MDMA contribuía com 1,1\%, o que, apesar de

\footnotetext{
${ }^{1}$ Pequena boate, pouco iluminada e que geralmente toca música em altíssimo volume.

2 Movimento ou grupo que atua fora do establishment, com ideias, postura e comportamento heterodoxos, vanguardistas ou radicais.

${ }^{3}$ Festas de musica eletrônica que ocorrem em sítios ou galpões, normalmente com doze ou mais horas de duração.
} 
parecer uma contribuição irrelevante, em números totais corresponde a aproximadamente 550 mil usuários (CEBRID, 2005). Assim sendo, consideramos que esta droga tem uma contribuição importante no contexto nacional do uso de drogas.

O uso abusivo de drogas é um fator importante na associação com doenças infecciosas e exposição à violência. (Carvalho, 1995; Carvalho et al., 2003). Consideramos para esse trabalho que, igualmente, o uso traz essa mesma associação.

O OBID faz uma síntese clara dos diferentes níveis de relação com a droga, propondo a seguinte divisão: uso experimental; uso recreativo; uso controlado; uso social, e, ainda, uso abusivo/nocivo de drogas. É definido como uso experimental o consumo de alguma droga especifica de forma extremamente infrequente ou não persistente. O uso recreativo se dá quando é feito em circunstâncias sociais ou relaxantes. O uso social é muito parecido com o recreativo, também sendo realizado em circunstâncias sociais e sem uma periodicidade definida. $\mathrm{O}$ uso controlado se refere à manutenção regular não compulsiva e que não interfere com o funcionamento habitual do indivíduo. O abuso/uso nocivo, ou ainda a dependência diz respeito a uma relação mais complexa com o uso de drogas. Para ele, temos duas fontes de definição: uma é o DSM-IV $\left(4^{a}\right.$ edição do Manual de Diagnóstico e Estatístico de Transtornos Mentais, da Associação Psiquiátrica Americana), que usa o termo 'abuso' e considera consequências sociais de um uso problemático e dá ausência da droga 
coloca fenômenos como tolerância e abstinência, o DSM-IV aborda os seguintes critérios:

1. Uso recorrente, resultando em fracasso em cumprir obrigações importantes relativas a seu papel no trabalho, na escola ou em casa;

2. Uso recorrente em situações nas quais isso representa perigo físico;

3. Problemas legais recorrentes relacionados à substância;

4. Uso continuado, apesar de problemas sociais ou interpessoais persistentes ou recorrentes, causados ou exacerbados pelos efeitos da substância.

O CID-10 (10ª Revisão da Classificação Internacional de Doenças da OMS), outro sistema classificatório que define abuso/uso nocivo ou dependência, caracteriza o uso nocivo como aquele que causa dano físico ou mental. Os critérios do CID-10 são:

1. Evidência clara de que o uso foi responsável (ou contribuiu consideravelmente) por dano físico ou psicológico, incluindo capacidade de julgamento comprometida ou disfunção de comportamento;

2. A natureza do dano é claramente identificável; 
3. O padrão de uso tem persistido por pelo menos um mês ou tem ocorrido repetidamente dentro de um período de 12 meses;

4. Não satisfaz critérios para qualquer outro transtorno relacionado à mesma substância no mesmo período (exceto intoxicação aguda) (OBID, 2011).

Os dois sistemas de classificação propõem quatro critérios. O DSM-IV complementa a indicação, informando que a definição de abuso se baseia a ocorrência de um ou mais critérios, no intervalo de doze meses.

Importantes estudos trazem uma correlação entre o uso de álcool e outras drogas e o comportamento sexual de alto risco de infecção em homens que fazem sexo com homens (HSH) (Parsons, et al., 2005; Patterson et al., 2005; Gondim, 2006). Embora haja uma associação empírica entre este grupo populacional e o uso de drogas recreativas, obtivemos um sucesso parcial no acesso à uma literatura específica a respeito de uso de drogas em população de $\mathrm{HSH}$ no Brasil. Discutiremos mais este aspecto no item metodologia.

Gondim (2006) demonstra uma relação clara entre a população HSH e o uso de drogas recreativas, ao afirmar que o consumo de drogas depressoras do Sistema Nervoso Central (SNC) entre a população de HSH do Ceará é um fator de risco para outros potenciais comportamentos vulneráveis. 
Mendoza-Pérez e Ortiz-Hernández (2009) afirmam que,

no caso dos $\mathrm{HSH}$, a vulnerabilidade social é derivada do estigma associado com suas práticas sexuais assim como as experiências de preconceito, discriminação e violência que com frequência são expostos ${ }^{4}$.

Como base no estigma descrito anteriormente, Barbosa e Malta nos indicam que essa é uma população com maior propensão a adquirir comportamentos de riscos, quando comparada à população heterossexual (Barbosa Junior, 2009. Malta et al., 2010).

Estudos nos EUA, Europa, México e Vietnã, demonstram que existe uma correlação positiva entre o uso de drogas e infecção pelo HIV na população de HSH. Clatts (2005a) descreve que o uso de drogas é prevalente em festas gays em Nova York. Schwarcz (2006), em São Francisco, e Kubicek et al. (2007), em Los Angeles, consolidam uma leitura sobre a tendência da correlação entre o uso de drogas e comportamento sexual de risco. Harawa (2008) descreve o mesmo comportamento de risco na África.

Os sujeitos da presente pesquisa compõem o segmento da população brasileira que tem como hábito sexual a prática homossexual, sendo denominados neste trabalho homens que fazem sexo com homem (HSH). Este segmento apresenta uma incidência 11 vezes maior de casos de AIDS comparado à população geral (Brasil 2008).

\footnotetext{
${ }^{4}$ En el caso de los HSH, la vulnerabilidad social es derivada del estigma asociado con sus prácticas sexuales así como las experiencias de prejuicio, discriminación y violencia que con frecuencia experimentan. (Mendoza-Pérez e Ortiz-Hernández, Rev. salud p 11 (5): 700-712, 2009)
} 
Discussão de Tobin e Latkin (2008) mostra a interseção entre afroamericanos que fazem uso de drogas injetáveis e o comportamento sexual de risco entre a população de $\mathrm{HSH}$ e de não HSH. Nguyen (2008) demonstra uma associação positiva em trabalho realizado no Vietnã entre usuários de drogas injetáveis na população de HSH.

Neste estudo, entendemos as diferenças entre os conceitos de risco epidemiológico e vulnerabilidade. Epidemiologicamente, pensamos no uso do conceito de risco, definido de maneira clara por Fletcher e Fletcher (2006), quando os mesmo consideram risco como a "probabilidade de que pessoas expostas a certos 'fatores de risco' subsequentemente desenvolvam uma determinada doença com maior frequência do que pessoas que não foram expostas". Parece ser a forma mais objetiva de associar o uso de drogas com o não uso de preservativo, e como essas associações dialogam com a literatura.

Considerando que essas práticas de sexo sem preservativo não são influenciadas somente pelo uso ou não de drogas, o uso do conceito de vulnerabilidade se faz também necessário.

Ayres (2003) considera o conceito de vulnerabilidade transversal aos "aspectos que vão de suscetibilidades orgânicas à forma de estruturação de programas de saúde, passando por aspectos comportamentais, culturais, econômicos e políticos."

Ayres et al (1999), observa que a mais importante transformação da maneira de pensar sobre o HIV, é sair do âmbito do risco individual atingindo o patamar de entender a epidemia como uma "vulnerabilidade social". 
Dessa maneira, entendemos que o conceito de vulnerabilidade, como colocado por Ayres (2002), vem "subsumir as ideias de grupo de risco e comportamento de risco à noção mais abrangente de vulnerabilidade; tomar os Direitos Humanos como critério fundamental para identificar e combater as diversas vulnerabilidades." Deixemos claro que o risco epidemiológico não vai ser abandonado neste trabalho, mas vamos endossar a discussão com a visão do conceito de vulnerabilidade.

Para melhor entender essa questão, usaremos a definição de vulnerabilidade usada por Ayres et al., (2003), que a consideram como os "três planos interdependentes de determinação e, consequentemente, de apreensão do comportamento pessoal ou a vulnerabilidade do indivíduo e da coletividade". Sánchez e Bertolozzi (2007), colocam da seguinte maneira os três eixos que envolvem a avaliação articulada de vulnerabilidade proposta por Ayres et al.:

\footnotetext{
(...) Nessa perspectiva, propõe a sua operacionalização através da Vulnerabilidade Individual, que se refere ao grau e à qualidade da informação que os indivíduos dispõem sobre os problemas de saúde, sua elaboração e aplicação na prática; a Vulnerabilidade Social, que avalia a obtenção das informações, o acesso aos meios de comunicação, a disponibilidade de recursos cognitivos e materiais, o poder de participar de decisões políticas e em instituições; e a Vulnerabilidade Programática, que
} 
consiste na avaliação dos programas para responder ao controle de enfermidades, além do grau e qualidade de compromisso das instituições, dos recursos, da gerência e do monitoramento dos programas nos diferentes níveis de atenção.

Esse cenário múltiplo e dinâmico mostra a necessidade de novas pesquisas que foquem grupos específicos como o dos $\mathrm{HSH}$, os quais adotam comumente práticas vulneráveis devido aos diversos fatores já apresentados, observando-se associações mais detalhadas em populações com maior vulnerabilidade e suas interações com o uso de substâncias psicoativas na aquisição do HIV. 


\section{Justificativa}

A escassez de estudos em âmbito nacional que tratam dessa temática torna o trabalho relevante. Sendo essa uma população inserida em contexto de vulnerabilidade amplamente conhecido, é possível perceber que o uso de drogas pode ser um fator que potencialize essas vulnerabilidades, mesmo sendo eles somente usuários recreativos de drogas psicoativas. Não se tem a pretensão de acessar a parcela da população que se enquadra nas definições de usuários abusivos, ou de uso nocivo, ou mesmo dependentes de drogas, por não ser foco deste estudo.

Este estudo propõe abordar o conceito de uso recreativo e/ou social de drogas, em um grupo $\mathrm{HSH}$, focando as associações com variáveis conhecidas de vulnerabilidade para aquisição de HIV e outras DSTs. 


\section{Objetivo Geral}

Explorar as vulnerabilidades em relação à aquisição do HIV e outras DSTs, influenciadas pelo uso recreativo de drogas psicoativas em um grupo de HSH da região metropolitana de São Paulo.

\section{Objetivos Específicos}

- Identificar o consumo de drogas psicoativas na população de HSH;

- Identificar as práticas sexuais e os comportamentos de riscos da população de HSH;

- Verificar as percepções da população HSH sobre a influência do uso de drogas estimulantes nas suas práticas sexuais. 


\section{Método}

Este é um estudo epidemiológico observacional do tipo transversal. População de estudo: homens que fazem sexo com homens residentes no município de São Paulo.

Amostragem e procedimentos: foi usada uma amostra de conveniência. No seu recrutamento foi utilizada a técnica de bola de neve a partir de um caso índice, no sentido de obter novos voluntários. Essa técnica, utilizada nas ciências sociais, consiste em um caso índice que indica novos casos a partir de seu relacionamento social, os quais indicam outros entrevistados, até atingir um número adequado de entrevistados (Thomas et al., 2009, Touko et al., 2010; Larmarange et al., 2010; van der Meer et al., 2010; Dumchev et al., 2009; Feng et al., 2010; Gondim et al., 2009).

\section{Instrumentos}

Foi utilizado um questionário para obtenção de dados demográficos, uso de drogas e comportamento de risco (Carvalho HB, 1995; Carvalho HB et al., 2003). O questionário é semiestruturado, com questões fechadas e abertas. É subdividido em 7 blocos (A a $G$ ).

Bloco $A$ foi trabalhado com base no questionário da Associação Brasileira de Empresas de Pesquisa (ABEP), para quem o questionário de Critérios de Classificação Econômica Brasil (CCEB) "enfatiza sua função de 
estimar o poder de compra das pessoas e famílias urbanas, abandonando a pretensão de classificar a população em termos de "classes sociais"' (ABEP, 2011). A divisão de mercado é definida por classes econômicas, tomando como base as pontuações informadas nos questionários e verificadas na Tabela 1, a seguir.

Quadro 1 - Classificação de renda da ABEP

\begin{tabular}{ccc}
\hline Classe & Pontos & $\begin{array}{c}\text { Renda Média Familiar } \\
\text { (valor bruto em R\$) } \\
\text { 2009 }\end{array}$ \\
\hline A1 & 42 a 46 & 11.480 \\
A2 & 35 a 41 & 8.295 \\
B1 & 29 a 34 & 4.754 \\
B2 & 23 a 28 & 2.656 \\
C1 & 18 a 22 & 1.459 \\
C2 & 14 a 17 & 962 \\
D & 8 a 13 & 680 \\
E & 0 a 7 & 415
\end{tabular}

Fonte: Abep, 2011

O Bloco C é uma reprodução na integra do teste de triagem do envolvimento com álcool, cigarro e outras substâncias (ASSIST) validado por Henrique (2004), com base no instrumento desenvolvido e proposto pela Organização Mundial da Saúde (OMS). O mesmo faz uma contagem de 
pontos de acordo com as respostas, para, em seguida, enquadrar o entrevistado em uma das seguintes categorias (Quadro 1):

Quadro 2 - Pontuação de envolvimento com uma substância especifica.

\begin{tabular}{llll}
\hline & Uso & Sugestivo & Sugestivo de \\
& Ocasional & de abuso & dependência \\
\hline Tabaco & $0-3$ & $4-26$ & 27 ou mais \\
Álcool & $0-10$ & $11-26$ & 27 ou mais \\
Maconha & $0-3$ & $4-26$ & 27 ou mais \\
Cocaína & $0-3$ & $4-26$ & 27 ou mais \\
Anfetaminas & $0-3$ & $4-26$ & 27 ou mais \\
Inalantes & $0-3$ & $4-26$ & 27 ou mais \\
Hipnóticos/sedativ & $0-3$ & $4-26$ & 27 ou mais \\
os & & $4-26$ & 27 ou mais \\
Alucinógenos & $0-3$ & $4-26$ & 27 ou mais \\
Opióides & $0-3$ & &
\end{tabular}

Fonte: Henrique, 2004

Ainda temos o bloco $\mathrm{G}$, que é uma entrevista semiestruturada com respostas abertas que também visam a verificar as percepções sobre a influência do uso de drogas estimulantes nas práticas sexuais e comportamentos vulneráveis. 
Os demais blocos foram adaptações dos questionários aplicados por Carvalho (1996) em trabalho com usuários de drogas injetáveis no porto de Santos.

Assim estão ordenados os referidos blocos:

Bloco A - Características sociodemográficas

Bloco B - Consumo de êxtase

Bloco C - Questionário para triagem do uso de álcool, tabaco e outras substâncias

Bloco D - Uso de êxtase na vida

Bloco E - Práticas de risco relacionadas ao comportamento sexual

Bloco F - Mudanças de comportamento e testagem de HIV

Bloco G - Percepções sobre o tema sexo e drogas

Critérios de inclusão: Pessoas que se identificassem como $\mathrm{HSH}$ e residissem na região Metropolitana de São Paulo.

Critério de exclusão: Indivíduos que estavam sob efeito de alguma substância psicoativa, de tal forma que pudesse comprometer a realização da entrevista. 


\section{Amostra}

Foi usada uma amostra de conveniência, com voluntários contatados pelo pesquisador em projetos realizados dentro do complexo do Hospital das Clínicas da Faculdade de Medicina da Universidade de São Paulo (HC FMUSP).

O tamanho da amostra foi determinado pelo esgotamento do discurso dos voluntários a respeitos das questões de interesse abordas no questionário.

\section{Entrevistas}

Após a aceitação de participar voluntariamente da pesquisa e a assinatura do Termo de Consentimento Livre e Esclarecido, foi aplicado o questionário por meio da técnica face-to-face (Catania, et al., 1990), com predomínio de questões fechadas, indo dos blocos A ao G (Anexo C).

O pesquisador foi responsável pelo preenchimento dos questionários. 


\section{Coleta de dados e análise estatística}

Os dados obtidos foram codificados, armazenados e analisados, utilizando-se o programa Excel e Stata@ 10.0 for Windows.

$\mathrm{Na}$ análise, foram utilizadas variáveis sociodemográficas (idade, sexo, cor, nível de escolaridade), além de variáveis de risco (quantidade de substância, uso de outras substâncias, uso de preservativo).

Primeiramente, foi realizada uma análise descritiva, utilizando-se medidas de frequência.

\section{Análise qualitativa}

Como descrito anteriormente, o Bloco $G$ contou com questões de resposta aberta, permitindo aos entrevistados expressar sua opinião de maneira ampla.

A análise dessas questões foi de conteúdo, descrita por Bardin (2011) da seguinte forma:

Um conjunto de técnicas de análise das comunicações, visando obter por procedimentos sistemáticos e objetivos de descrição do conteúdo das mensagens indicadores (quantitativos ou não) que permitam a inferência de conhecimentos relativos às 
condições de produção/recepção (variáveis indeferidas) dessas mensagens.

Ainda como proposto por Bardin, as entrevistas foram transcritas em sua integralidade, e, para iniciar a análise, reunimos as respostas das questões 4 e 5 em um bloco e as questões 6 e 7 em outro. As questões 1, 2 e 3 foram tratadas de forma individual. Utilizamos essa estratégia para obter um maior conteúdo de análise.

O processo de categorização se deu a partir da leitura repetitiva dos conteúdos. As categorias não foram previamente propostas, mas obtidas a partir do próprio processo analítico. A busca por categorias analíticas nos levou ao uso de termos como conservador, moderado e liberal. O sentido dos termos está associado diretamente à pergunta e a prática dos sujeitos da pesquisa. O uso desses termos não conota juízo de valor a respeito de suas práticas ou opiniões. Por exemplo, entendemos que sujeitos com experiência positiva no uso de drogas adotam uma posição mais liberal, no sentido de uso de substâncias ilícitas. Não estamos fazendo qualquer indicação de que ser liberal é melhor ou pior do que ser conservador. O uso dos termos foi no intuito de identificar uma característica comum nas falas dos sujeitos. 


\section{Considerações Éticas}

O projeto foi submetido e aprovado pela Comissão de Ética para Análise de Projetos de Pesquisa (CAPPesq) do HC-FMUSP (Anexo A). Todos os dados coletados foram tratados com confidencialidade e foram adotadas medidas para mitigar qualquer possível situação que expusesse informações identificáveis desses indivíduos a pessoas alheias à pesquisa. 


\section{Resultados}

\section{Caracterização do Grupo}

O grupo é formado por 34 indivíduos, sendo que 94\% (32) são solteiros e 2 estão em união estável. A média de idade é de 35 anos (desvio padrão 6.6), sendo que brancos compõem $67 \%$ (23). Setenta por cento (24) apresentam nível superior e, em relação à renda, estão agrupados nas classes B1 e B2, com 32\% e $44 \%$ respectivamente (11 e 15), segundo o CCEB (Figura 1).

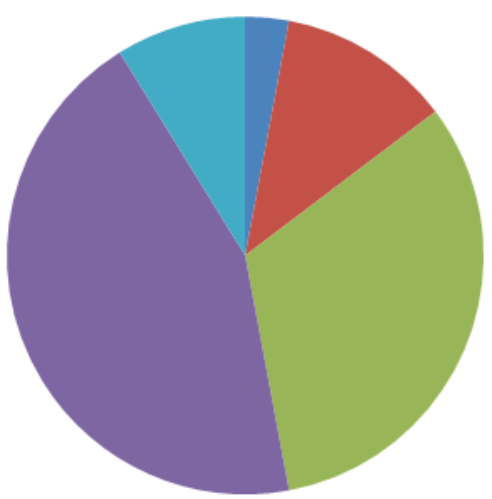

A1(Renda familiar média 11.480)

- A2(Renda familiar média 8.295)

B1(Renda familiar média 4.754)

- B2(Renda familiar média 2.256)

- C1(Renda familiar média1.459)

Figura 1. Classificação segundo o CCEB

Uso de drogas

Foram entrevistados os 34 sujeitos, dos quais 3 relataram nunca ter usado qualquer tipo de droga psicoativa na vida. Os dados referentes a uso de drogas baseiam-se em um total de 31 sujeitos. 
Os dados obtidos com a aplicação do Assist demonstraram que 41\% (13) dos sujeitos da pesquisa fizeram uso de anfetaminas ou êxtase ao menos uma vez na vida. Dentre as demais drogas ilícitas, a mais usada foi a maconha, com 58\% (18). Dentre as drogas lícitas, o álcool aparece em primeiro lugar, com 94\% (30), como observado na Figura 2.

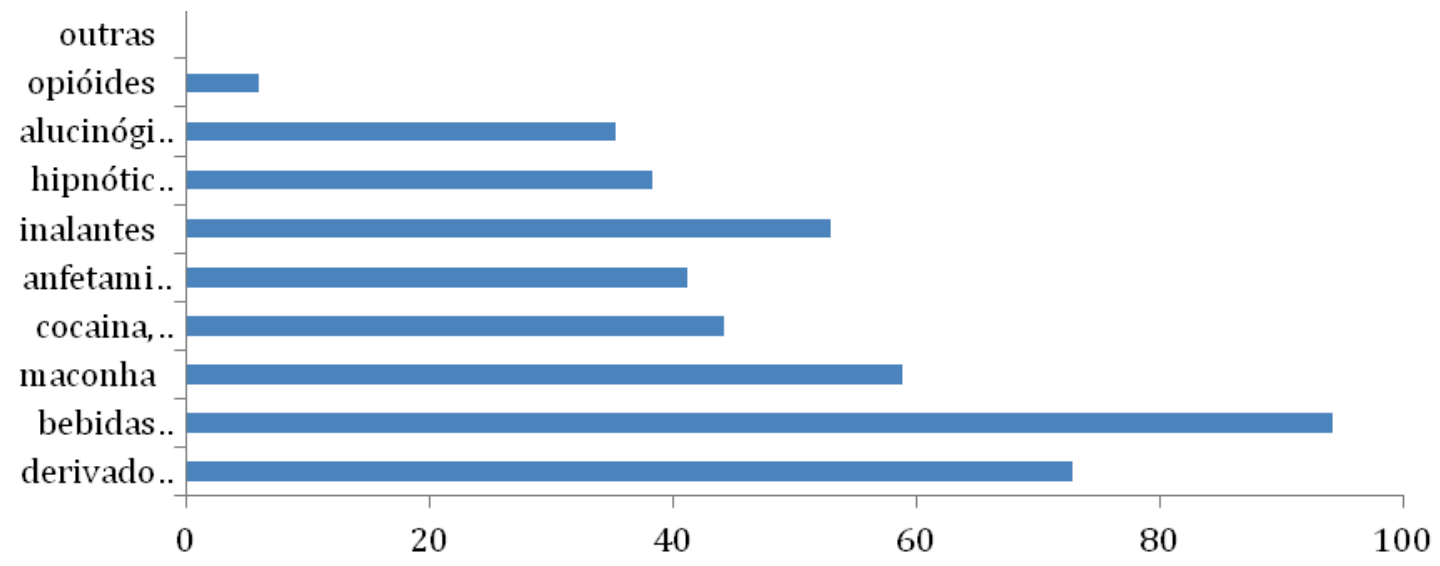

Figura 2. Uso de drogas psicoativas na vida

Na Figura 3, podemos ver o uso dessas substâncias nos três meses que antecederam a pesquisa, divididas em quatro categorias de frequência (1 ou 2 vezes; mensalmente; semanalmente, e diariamente/quase todos os dias). Pôde-se observar que o uso das anfetaminas ou êxtase ocorreu poucas vezes nesse período; o álcool apareceu com a mesma equivalência no mesmo período, e, adicionalmente, como a substância mais usada, considerando as categorias "mensalmente" e "semanalmente". Na categoria "diariamente/quase todos os dias", os derivados de tabaco apareceram de forma majoritária com $24 \%$. Na sequência, veio o uso de maconha, com 
$11 \%$. O álcool só voltou a aparecer como terceira substância, com $6 \%$ de sujeitos declarando fazer uso dele nessa frequência. Cabe lembrar que, na questão dois, se o sujeito respondesse "nunca" para todas as drogas, automaticamente iria direto para a questão 6 . Isso explica o número menor de respostas quando comparado à primeira questão.

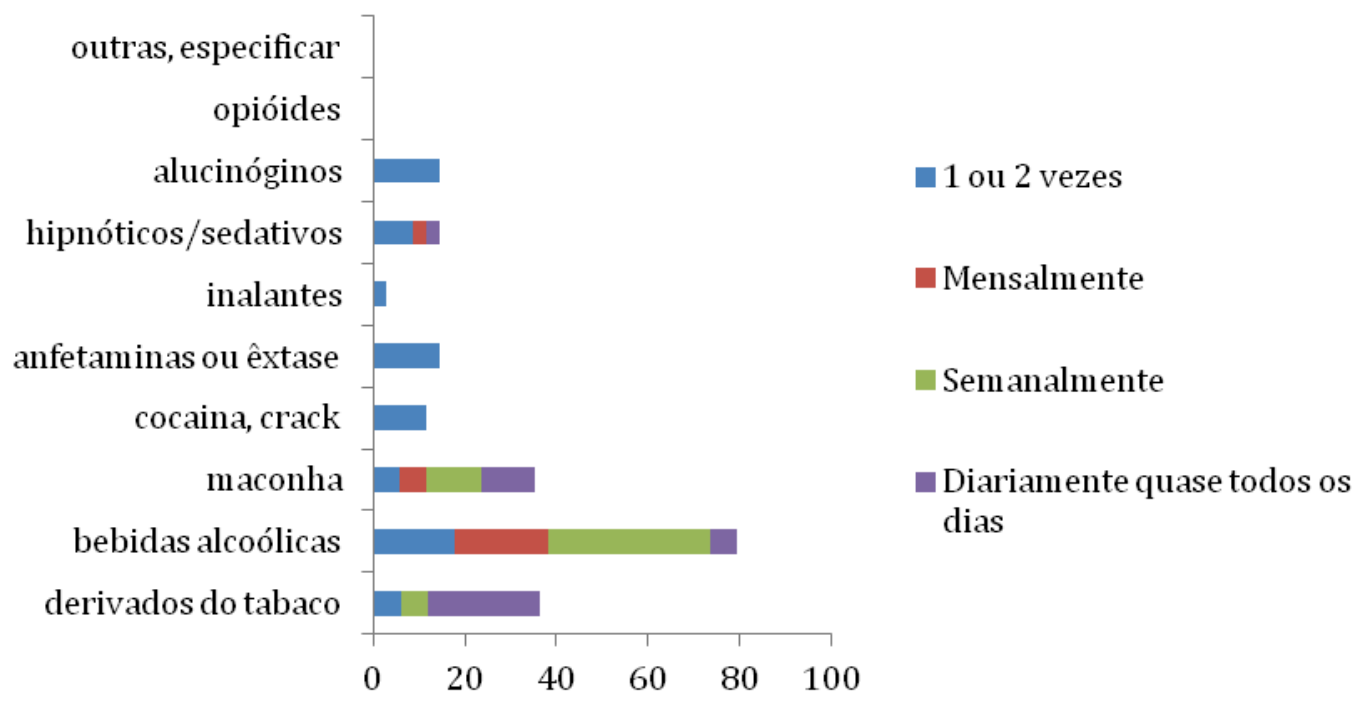

Figura 3. Frequência de uso de drogas psicoativas

O desejo de consumir anfetaminas ou êxtase nos três meses anteriores ao estudo, como apresentado na Figura 4, foi o maior entre as drogas ilícitas (9\%), quando visualizada a frequência "1 a 2 vezes". Quando olhamos para os outros períodos, podemos ver que, na categoria "mensalmente", apenas o êxtase e a maconha apareceram, com a mesma proporção de $3 \%$ para cada um. Nos outros períodos, a maconha apareceu como sendo a única droga ilícita, e, quando vista isoladamente, a frequência 
"diariamente quase todos os dias", apareceram somente duas substâncias: os derivados de tabaco, com $21 \%$, e a maconha, com $12 \%$.

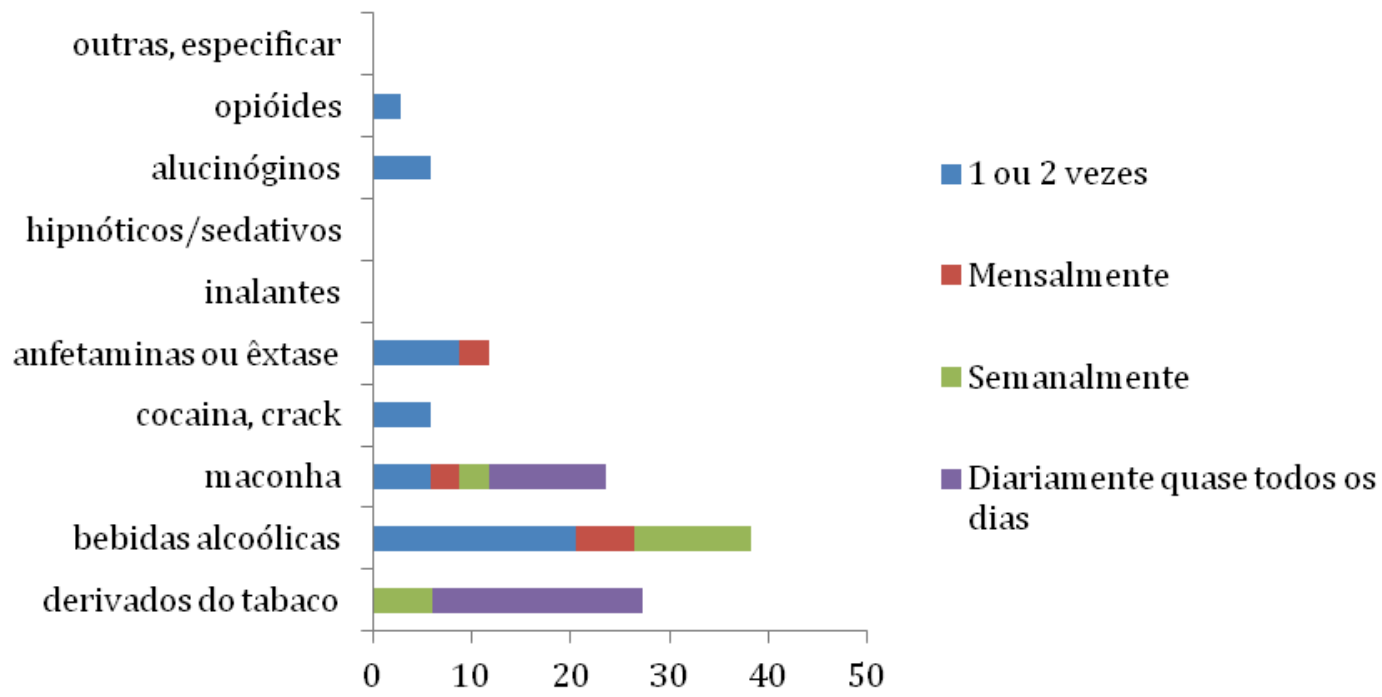

Figura 4. Forte desejo ou urgência em consumir drogas psicoativas

Quando pensado se o uso dessas substâncias resultou em algum problema, se resultou em problema de saúde, social, legal ou financeiro, a Figura 5 mostra que somente duas drogas são citadas: o álcool e a maconha. Mesmo assim, nenhuma delas aparece na frequência "diariamente/quase todos os dias" A maior porcentagem se deu com álcool (9\%), na categoria "1 ou 2 vezes". 


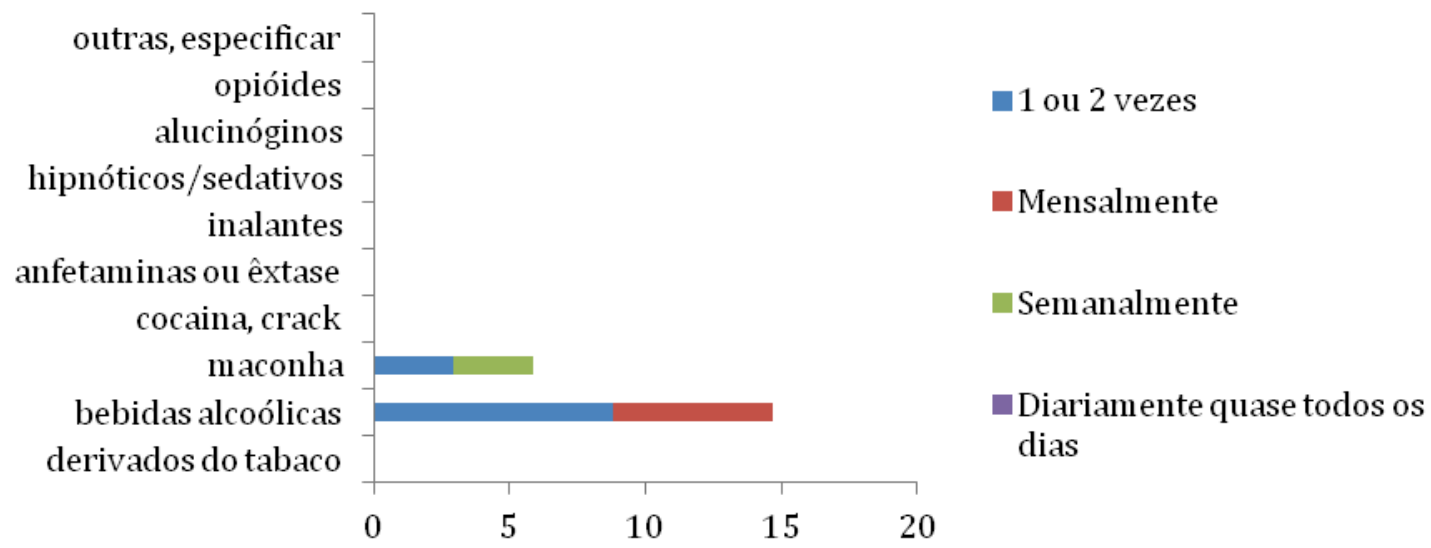

Figura 5. Consumo de drogas psicoativas resultou em problema de saúde, social, legal ou financeiro

Sob perspectiva semelhante, a Figura 6 mostra se os voluntários deixaram de fazer coisas que eram normalmente esperadas deles. Assim como anteriormente, tivemos uma baixa proporção em poucas categorias (1 ou 2 vezes e semanalmente), sendo que o álcool apareceu como a maior (15\%), na categoria "1 ou 2 vezes", e a maconha (6\%), na categoria "semanalmente".

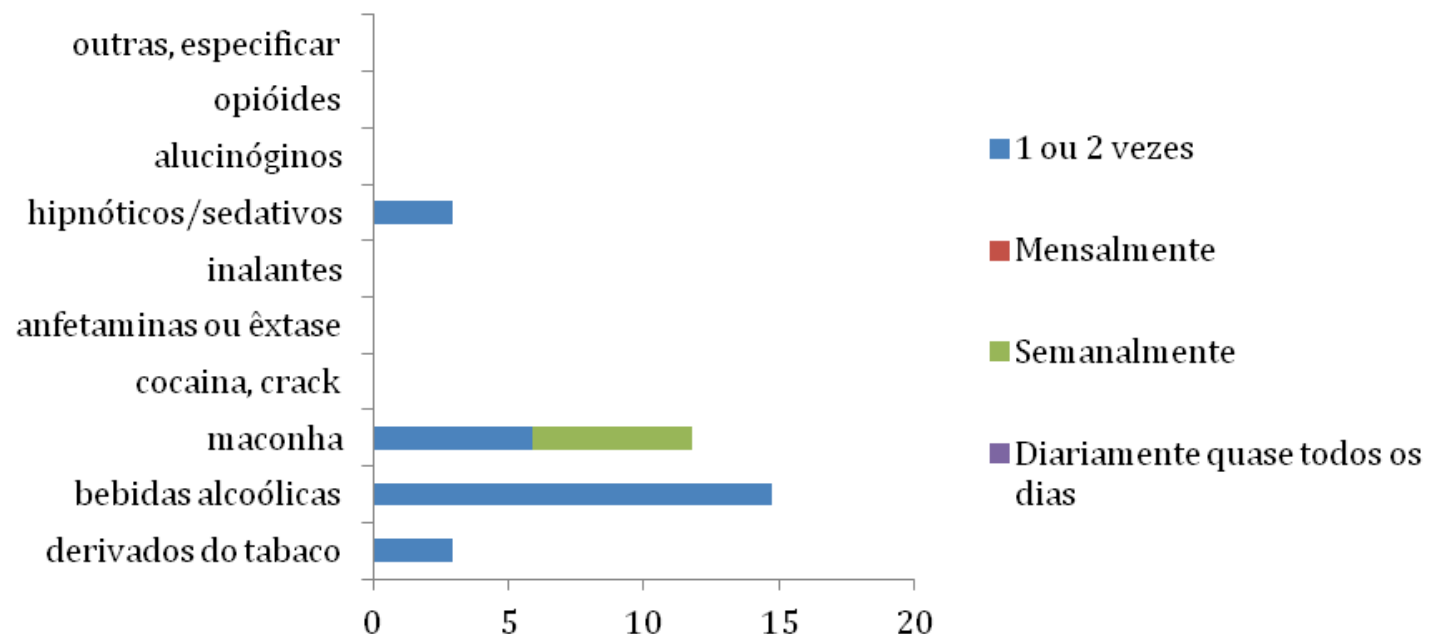

Figura 6. Drogas psicoativas interferindo nas atividades cotidianas 
$\mathrm{Na}$ Figura 7, vemos como os sujeitos perceberam que amigos, parentes ou outra pessoa tivesse demonstrado preocupação com seu uso de alguma substância. As únicas drogas ilícitas que apareceram foram a maconha e os opióides. Quando vistas as categorias de forma separada, o álcool aparece como maior fonte de preocupação, com 12\%, na categoria "Sim, últimos 3 meses" e o tabaco, com 15\%, na categoria "Sim, mas não nos últimos 3 meses".

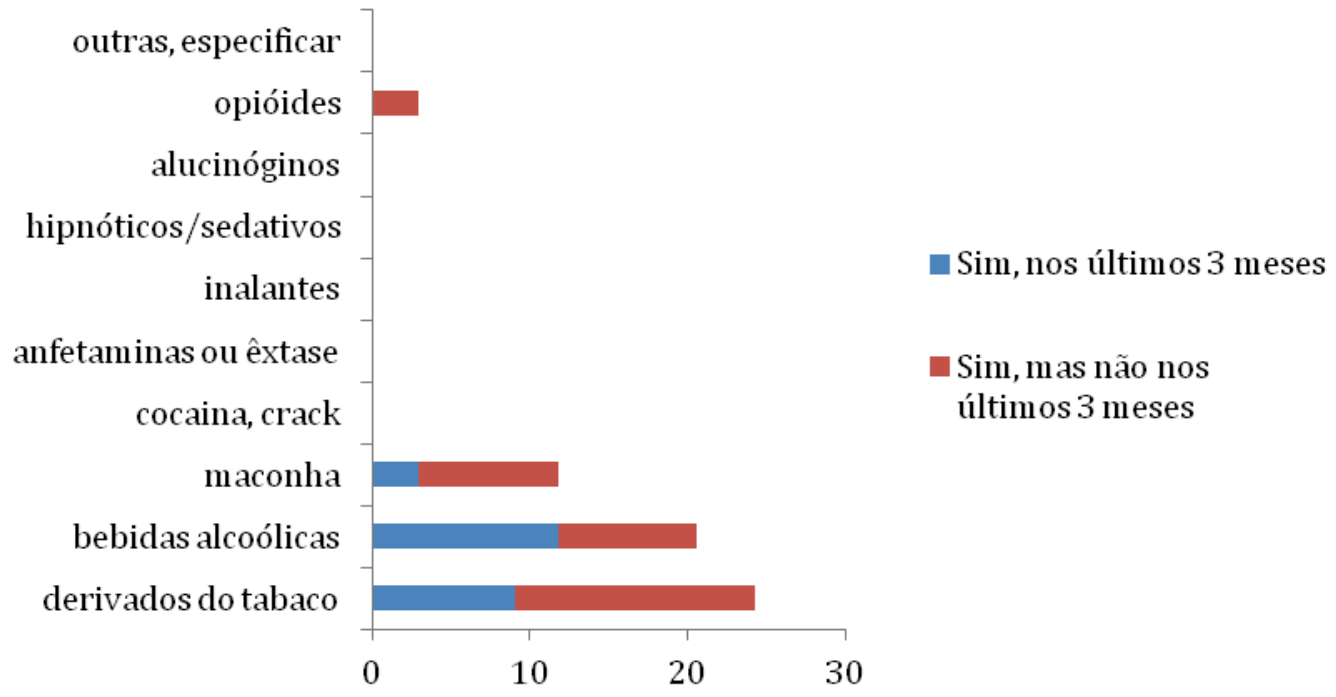

Figura 7. Preocupação com o uso de drogas psicoativas

Ao pensamos nas tentativas de controlar, diminuir ou eliminar o uso de alguma substância sem sucesso, a Figura 8 mostra que somente três substâncias apareceram na categoria "Sim, últimos 3 meses", sendo derivados de tabaco (3\%), álcool e maconha ( ambas com 6\%). Na categoria "Sim, mas não nos últimos 3 meses", aparecem os hipnóticos/sedativos 
(6\%). Os derivados de tabaco, álcool e maconha se repetem, com 15\%, $9 \%$ e $9 \%$ respectivamente.

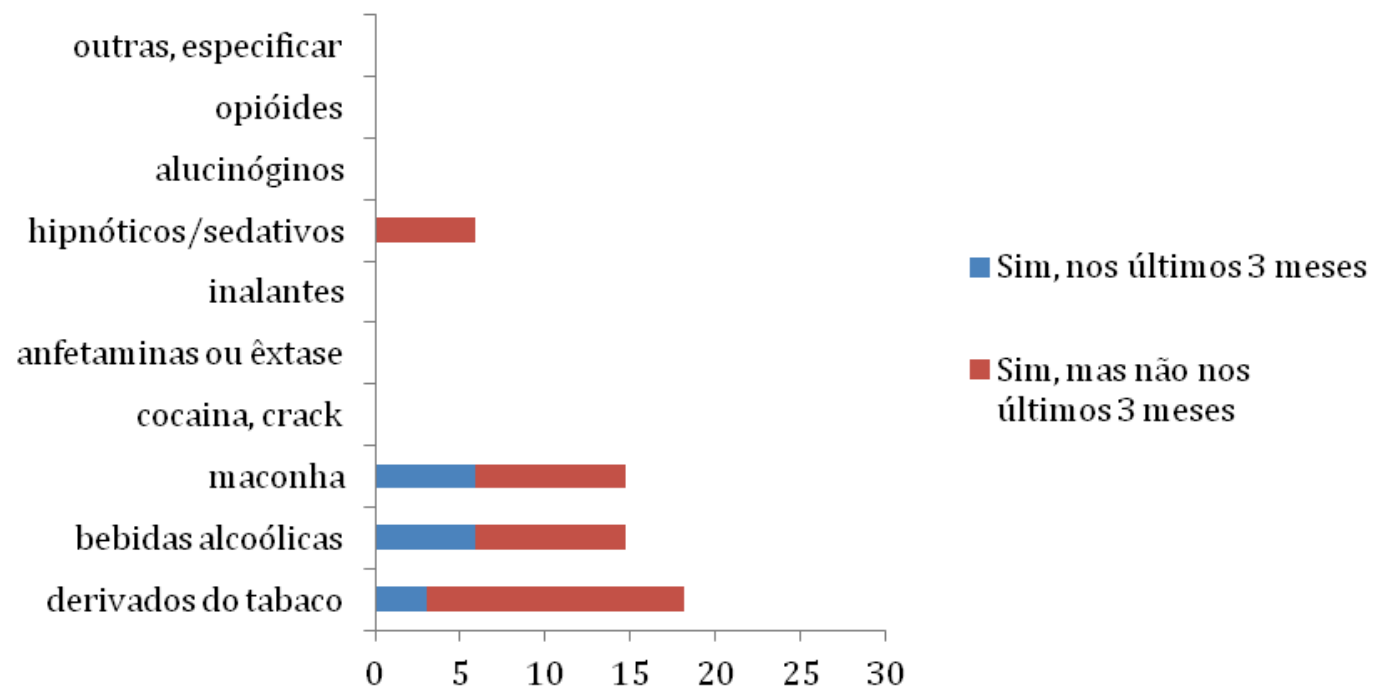

Figura 8. Diminuição ou parada o uso de alguma droga psicoativa

Sendo o Assist um questionário de rastreamento que visa a identificar como o consumo pode necessitar de algum tipo de intervenção, podemos ver pela Figura 9 que somente 3\% (1) de usuários de álcool e maconha apresentaram um apontamento de possível dependência. Nenhum dos sujeitos se enquadrou na categoria de usuário ocasional (pontuação total no questionário de 27 ou mais). 


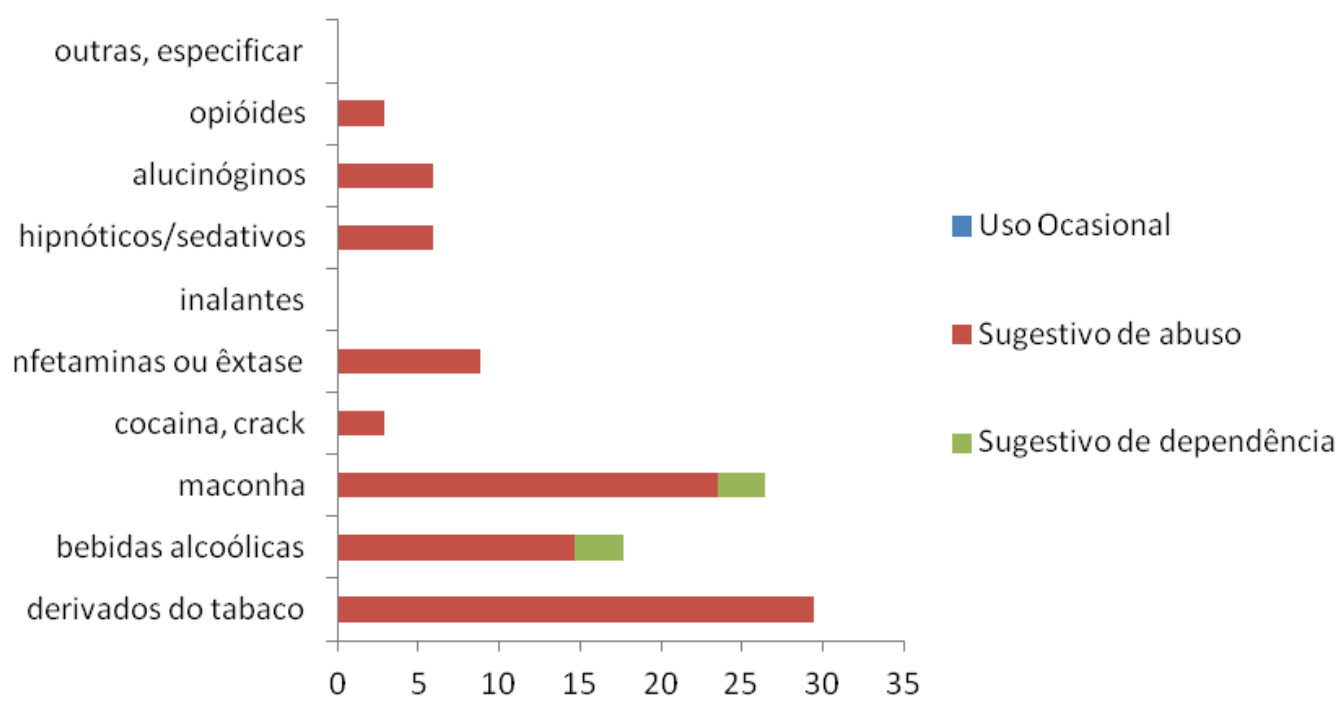

Figura 9. Pontuação total do Assist

A última questão do Assist aborda do uso de drogas por injeção. Somente 3\% (1) declararam fazer uso, na categoria "Sim, mas não nos últimos 3 meses".

Quando pensamos em uso de êxtase na vida, apenas $35 \%$ (12) dos sujeitos declararam fazer esse uso, e, destes, cerca de $58 \%$ (7) tomaram apenas 1 comprimido na ocasião. Os quatro motivos citados para o uso foram: curiosidade $75 \%$ (9); porque é legal 58\% (7); porque meu(s) amigo (s)/parceiro(s) usa(am) 50\% (6), e porque sempre uso $8 \%$ (1). Lembrando que, nessa questão, o sujeito poderia marcar mais de uma resposta, nenhum deles referiu o uso de êxtase nos 15 dias que antecederam a entrevista.

Quando questionados sobre o local de uso, o mais frequente foi: em bares, boates e festas com $67 \%$ (8). Outros locais foram: na casa de 
amigos/namorado, na rua/praças/becos e em outros lugares quaisquer, totalizando $50 \%$ (6). Essa é uma questão que permitia também mais de uma resposta.

Na questão que se refere a como foi obtido o êxtase, o sujeito poderia marcar mais de uma resposta. Com isso, obtivemos os seguintes resultados: todos ganharam ou compraram êxtase de traficante, parceiro ou amigo ao menos uma vez.

Nenhum desses sujeitos mencionou ter usado sexo para conseguir a droga, ou que a mesma mudou a frequência de suas relações sexuais, na ocasião do uso.

Quanto ao consumo concomitante de outras drogas, foi possível perceber que todos fizeram isso. A maioria fez uso concomitante de álcool e maconha, $75 \%$ e $58 \%$ (9 e 7 respectivamente). Nessa questão, os sujeitos eram orientados a referir todas as drogas que tivessem usado na ocasião. A Figura 10 facilita a visualização do consumo concomitante de outras drogas.

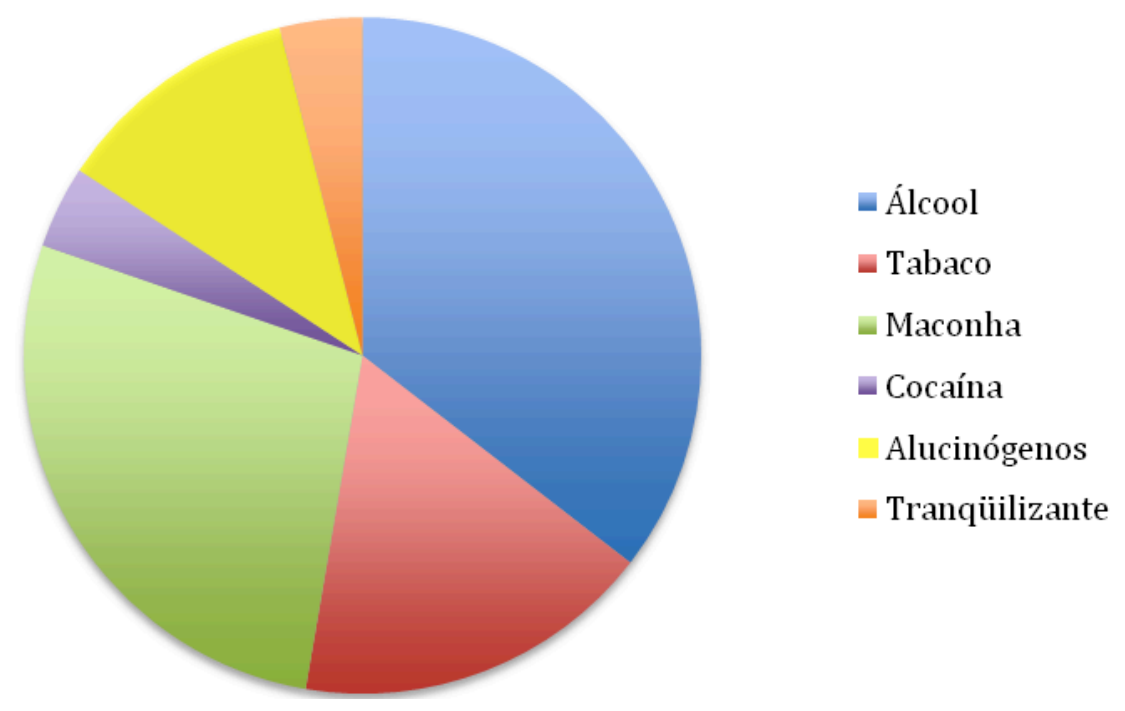

Figura 10. Uso concomitante de outras drogas 
Dentre os sujeitos que referiram fazer uso de êxtase, apenas $8 \%$ (1) disseram ter alteração no consumo de outras drogas, (álcool aumentado), quando questionados se seu consumo de outras drogas tinha sido alterado, sendo a modificação na frequência do uso. A outra mudança referida foi parar de usar. As drogas que entraram nesse grupo foram: o tabaco, a maconha, a cocaína, o mesclado e os inalantes.

No bloco de praticas de risco relacionadas ao comportamento sexual, todos afirmaram já ter feito sexo na vida. O número médio de parceiros no mês foi de 6 . Esse valor é deslocado da mediana, de 1.5 parceiros, por conta de três voluntários que tiveram 20 ou mais parceiros e elevaram demasiadamente o valor da média.

O uso intermitente do preservativo foi relatado por $91 \%$ (31) dos sujeitos. Somente 3\% (1) disseram nunca fazer uso de preservativo e $6 \%$ (2) relataram fazer uso constante do preservativo.

De todos os sujeitos da pesquisa, $18 \%$ (6) relataram ter recebido alguma vez de alguma pessoa presente, dinheiro, bens ou drogas em troca de relação sexual. Dos 18\% (6) que declaram essa prática, 67\% (4) relataram que a frequência era quase nunca, e 33\% (2) relataram que isso acontecia às vezes. Somente $17 \%$ (1) colocaram que quase nunca usavam preservativo nesse tipo de relação. Ao serem questionados sobre preocupação com o HIV nessas relações, $71 \%$ disseram se preocupar.

Apenas um de todos os entrevistados disse fazer sexo com mulheres, e o mesmo não relatou qualquer modificação nas práticas sexuais, uso de 
drogas ou preocupação com o HIV, quando referida a prática sexual com mulheres.

No bloco de mudanças de comportamento e testagem de HIV, todos os sujeitos relataram já ter feito testagem. Cinquenta e nove por cento $(59 \%)$ (20) relataram já ter ido a um Centro de Testagem e Aconselhamento (CTA), e $91 \%(31)$ relataram que participaram de alguma atividade de prevenção nos 12 meses que antecederam a entrevista. Sobre as sorologias, 15\% (5) relatam serem soropositivos; 79\% (27) relataram ser soronegativos, e 6\% (2) disseram não saber ou não quiseram responder.

Ao usarmos uma variante de escala análoga visual para autoclassificação do risco de contrair HIV nos doze meses que viriam após a entrevista, categorizada como baixo risco (percentil 25), médio risco (percentil 50) e alto risco (percentil 75 ou maior), obtivemos os seguintes resultados demonstrados na Figura 11, de acordo com os percentil para avaliar a percepção de riscos.

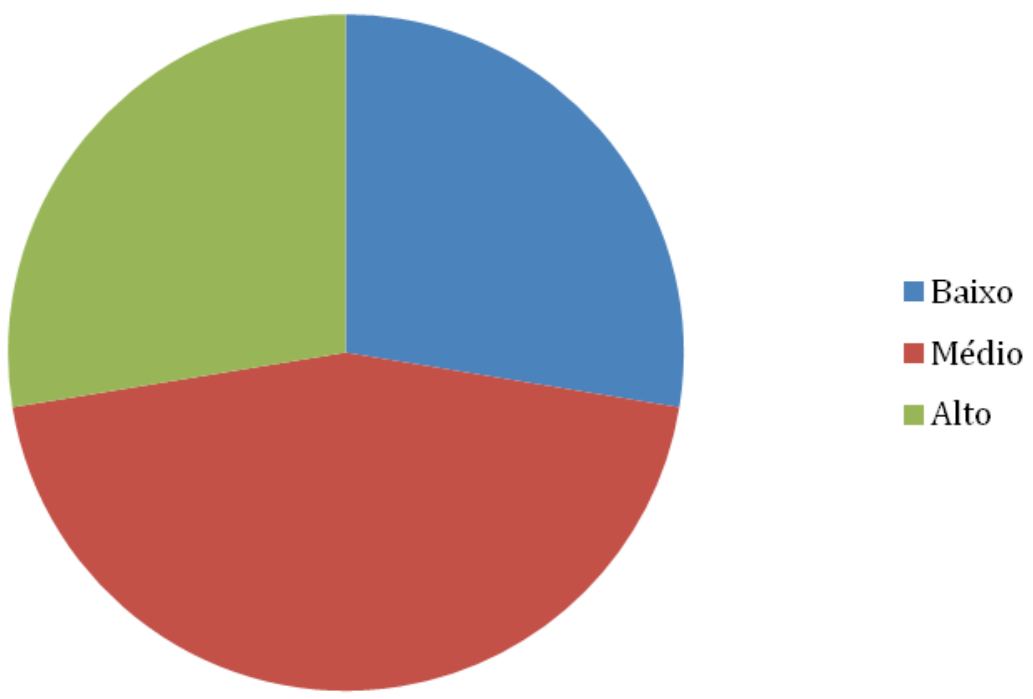

Figura 11. Percentil de risco de contração de HIV nos próximos 12 meses(Baixo:27,6\%, Médio:44,8\%, Alto:27,6) 
Foi possível observar que, dentre os não infectados, a maior faixa se autoavalia com risco médio ou baixo de contrair HIV nos 12 meses seguintes. 


\section{Resultados Qualitativos}

As entrevistas foram analisadas com uma participação de $97,06 \%$ (33) dos sujeitos. Apenas um voluntário se recusou a responder esse bloco de questões, alegando falta de tempo.

Os resultados das análises dos conteúdos das entrevistas trouxeram três concepções distintas da ideia de uso de drogas. Podemos ver no Quadro 3, as três opiniões que mais representam cada uma das três categorias (liberais, moderados e conservadores), em relação à questão 1 , em que os sujeitos foram questionados sobre sua opinião a respeito das drogas, em um contexto geral. Na categoria liberais, tivemos $12,12 \%$ (4). A participação dos voluntários na categoria moderados foi de $48,48 \%$ (16) e na de conservadores foi de $39,40 \%(13)$.

Quadro 3. Opinião sobre o uso de drogas

\begin{tabular}{llcl}
\hline $\begin{array}{l}\text { Características } \\
\text { associadas ao } \\
\text { tema central }\end{array}$ & Visão sobre o uso de drogas & Sequência & Análise temática \\
\hline Liberal & $\begin{array}{l}\text { (...) a química a serviço da } \\
\text { vida. }\end{array}$ & 1 & $\begin{array}{l}\text { Experiência } \\
\text { positiva }\end{array}$ \\
Moderado & $\begin{array}{l}\text { (drogas) que só destroem a } \\
\text { vida da pessoa (...) se souber } \\
\text { levar, acaba não tendo um } \\
\text { prejuízo na vida pessoal (...). }\end{array}$ & 2 & $\begin{array}{l}\text { Responsabilização } \\
\text { do individuo }\end{array}$ \\
Conservador & Horrível. & 3 & Visão negativa
\end{tabular}


Na sequência, os sujeitos foram questionados sobre o uso de drogas nas baladas. Usamos novamente as categorias liberais, moderados e conservadores, com $27,3 \%$ (9), 18,2\% (6), 54,5\% (18) respectivamente. O Quadro 4 mostra as falas mais expressivas de cada categoria.

Quadro 4. Visão sobre o uso de drogas em casas noturnas

\begin{tabular}{llcl}
\hline $\begin{array}{l}\text { Características } \\
\text { associadas ao tema } \\
\text { central }\end{array}$ & Drogas e "baladas" & Sequência & $\begin{array}{l}\text { Analise } \\
\text { temática }\end{array}$ \\
\hline $\begin{array}{l}\text { Liberal } \\
\text { Moderado }\end{array}$ & $\begin{array}{l}\text { É o local mais apropriado. } \\
\text { Dependendo no nível de } \\
\text { droga, não sei se tem } \\
\text { problema. } \\
\text { Para mim que usa droga é } \\
\text { doente. }\end{array}$ & 2 & $\begin{array}{l}\text { Favorável } \\
\text { Opcional }\end{array}$ \\
Conservador & & 3 & Desfavorável \\
\hline
\end{tabular}

Ao perguntamos a opinião dos sujeitos sobre o uso de drogas e fazer sexo, obtivemos três categorias principais de análise. Tivemos os favoráveis, com $12,1 \%(4)$; os que relativizaram o uso das drogas, com $36,4 \%(12)$, e, ainda, os que se declararam contra a combinação de drogas e sexo, com 51,5\%(17). O Quadro 5 traz as falas icônicas a respeito do tema. 
Quadro 5. Usar drogas e fazer sexo

\begin{tabular}{llcl}
\hline $\begin{array}{l}\text { Características } \\
\text { associadas ao } \\
\text { tema central }\end{array}$ & Drogas e sexo & Sequência & $\begin{array}{l}\text { Analise } \\
\text { temática }\end{array}$ \\
\hline Favorável & $\begin{array}{l}\text { Unir o útil ao agradável. Muito } \\
\text { bom. }\end{array}$ & 1 & Favorável \\
Relativiza & $\begin{array}{l}\text { (..) influencia numa desproteção } \\
\text { do sexo (...). A pessoa tem que } \\
\text { estar realmente bem estruturada, } \\
\text { psicologicamente para ela } \\
\text { conseguir segurar a barra. } \\
\text { (...) como é uma doença, e essa } \\
\text { doença que faz parte do ser da } \\
\text { pessoa, ela carrega pra tudo que } \\
\text { é lugar. Enfim, ela carrega para o } \\
\text { almoço, ela carrega para o } \\
\text { jantar, ela carrega para o sexo. }\end{array}$ & 2 & Relativiza \\
& & & \\
& & Desaprova \\
& & & \\
\hline
\end{tabular}

A quarta pergunta questionava como eles percebiam se as drogas influenciavam na ereção, e se isso já tinha acontecido com eles em alguma situação. A quinta pergunta era sobre sexo sem ereção. Para essas questões, surgiram duas categorias favoráveis e desfavoráveis, com 6,1\% (2) e $93,9 \%$ (31) respectivamente. No Quadro 6, podemos ver as falas mais representativas.

Quadro 6. Influência das drogas na ereção e no sexo

\begin{tabular}{llcl}
\hline $\begin{array}{l}\text { Características } \\
\text { associadas ao } \\
\text { tema central }\end{array}$ & Ereção, drogas e sexo & Sequência & $\begin{array}{l}\text { Analise } \\
\text { temática }\end{array}$ \\
\hline Favorável & $\begin{array}{l}\text { Aumenta o tesão, e com isso } \\
\text { acaba aumentando a ereção. }\end{array}$ & 1 & Favorece \\
Desfavorável & $\begin{array}{l}\text { Às vezes perde a concentração e } \\
\text { começa a brochar, sim (...). }\end{array}$ & 2 & Prejudica \\
\hline
\end{tabular}


As questões seis e sete abordaram o uso de preservativo e o conhecimento sobre outras estratégias de prevenção. Dividimos as respostas em três categorias: uso inconstante de preservativo, 30,3\%(10); uso constante de preservativo, 30,3\%(10), e não uso de preservativo, $39,4 \%(13)$. O Quadro 7 coloca as falas mais representativas.

\section{Quadro 7. Uso de drogas e prevenção}

\begin{tabular}{|c|c|c|c|}
\hline $\begin{array}{c}\text { Características } \\
\text { associadas ao tema } \\
\text { central }\end{array}$ & Drogas e prevenção & Sequência & Analise temática \\
\hline $\begin{array}{l}\text { Uso inconstante de } \\
\text { preservativo }\end{array}$ & $\begin{array}{l}\text { (...) acho que depende, algumas } \\
\text { drogas alteram tanto a } \\
\text { consciência humana, que pode } \\
\text { deixar a pessoa meio displicente } \\
\text { ali, num momento ou outro. E, no } \\
\text { calor da emoção, esquecer desse } \\
\text { detalhe. } \\
\text { (...) Mas em relação à AIDS, eu } \\
\text { achava que era só a camisinha } \\
\text { mesmo. }\end{array}$ & 1 & $\begin{array}{l}\text { Não usa, } \\
\text { preservativo }\end{array}$ \\
\hline $\begin{array}{l}\text { Uso constante de } \\
\text { preservativo }\end{array}$ & $\begin{array}{l}\text { (...) é o mesmo que acontece com } \\
\text { a bebida, as pessoas têm vontade } \\
\text { de determinadas coisas, dentre } \\
\text { elas pode ser não usar camisinha; } \\
\text { e a hora que usa substâncias que } \\
\text { alteram, vai no embalo. Não } \\
\text { transar. }\end{array}$ & 2 & $\begin{array}{l}\text { Relativiza o uso, } \\
\text { abstinência. }\end{array}$ \\
\hline $\begin{array}{l}\text { Não uso de } \\
\text { preservativo }\end{array}$ & $\begin{array}{l}\text { Eu acho que a maioria das vezes } \\
\text { não. Métodos bobos, de tentar } \\
\text { evitar ejacular dentro (...). Não } \\
\text { acredito em nenhum remédio que } \\
\text { seja tomado, tipo, pílula do dia } \\
\text { seguinte para não pegar HIV. Não } \\
\text { acredito que exista isso. }\end{array}$ & 3 & $\begin{array}{l}\text { Não usa, redução } \\
\text { de danos }\end{array}$ \\
\hline
\end{tabular}




\section{Discussão}

O presente estudo identificou características de uso e opiniões sobre o uso de drogas psicoativas e sua correlação com práticas sexuais em uma população de HSH.

Buscar um perfil de drogas usadas por este grupo nos mostra caminhos para trabalhar a prevenção de enfermidades e entender questões de vulnerabilidades ligadas a essa população.

Estudo no Ceará (Gondim et al., 2006) mostra que 31\% dos sujeitos pesquisados relataram ter usado maconha nos 12 meses que antecederam a investigação. Na população do presente estudo, quase $40 \%$ fizeram uso ao menos uma vez nos três meses que antecederam o estudo. A maconha se mostra, portanto, como a droga ilícita mais usada nos dois períodos. Comparativamente, $80 \%$ dos sujeitos dos dois estudos fizeram uso de álcool, colocando o álcool como a droga lícita mais usada. Outras drogas, como o êxtase, aparecem em aproximadamente $20 \%$ dos sujeitos nos dois estudos. Essa mesma característica aparece em dois estudos realizados na cidade de Nova York (Halkitis et al., 2006; Clatts; Goldsamt; Yi, 2005b).

O relatório técnico sobre o Assist (Humeniuk; Ali, 2006) em sete países (Austrália, Brasil, Índia, Tailândia, Reino Unido, Estados Unidos e Zimbábue) mostra similaridades em relação às populações de estudo. 
Encontramos que quase a totalidade dos sujeitos da pesquisa se encontrava na categoria de intervenção leve, quando avaliada a pontuação do Assist.

Quando observadas as especificidades em relação ao êxtase, podemos ver que estudos em Nova York (Halkitis et al., 2006; Clatts; Goldsamt; Yi, 2005b) apontam uma faixa muito similar à encontrada neste estudo, com uso de 35\%. O I Levantamento Nacional sobre o Uso do Álcool, Tabaco e Outras Drogas entre Universitários nas 27 Capitais Brasileiras (Brasil, 2010), mostra o êxtase como a quarta droga mais usada em concomitância com o álcool.

No presente estudo, também encontramos uso frequente de álcool e êxtase entre os sujeitos da pesquisa. $\mathrm{O}$ álcool foi a droga concomitante mais usada (Figura 11), semelhante aos dados do levantamento entre universitários (Brasil, 2010). O uso se deu historicamente em bares/boates/festas. Vemos que o local de uso e a forma de conseguir a droga foram similares para a quase totalidade dos sujeitos que referiram o uso (Almeida; Silva,. 2003; Halkitis et al., 2006; Clatts; Goldsamt; Yi, 2005b).

A literatura confirma a tendência (Henrique et al., 2004; Scivolleto et al., 1999) de o álcool ser a droga lícita mais usada em concomitância com outras drogas. A maconha é a droga ilícita mais usada concomitantemente com outras drogas.

O número de parceiros sob o efeito de drogas esteve na mesma escala que a de estudo de Clatts, Goldsamt e Yi, em Nova York (2005a). 
Quando nos concentramos no bloco de práticas sexuais, podemos ver que um fator muito mais chamativo do que o número de parceiros - o qual está muito próximo do número encontrado em homossexuais e bissexuais em estudo de Andrade et al. (2007), ou abaixo, como apontado por Brignol e Dourado (2011) - é o uso do preservativo, sendo que $91 \%$ dos sujeitos indicaram uso intermitente. Na literatura, encontramos estudos que apontam para uma proporção de até 35\% (Andrade et al., 2007; Brignol e Dourado, 2011). Nosso elevado valor pode ser justificado por um viés de seleção e pelas limitações da técnica escolhida para o recrutamento (Dunn; Ferri, 1999).

A Pesquisa de Conhecimento Atitudes e Práticas da População Brasileira em relação a HIV, Hepatites virais e DSTs (PCAP, 2008) coloca ainda que apenas $3,8 \%$ dos homens em idade sexualmente ativa já foram alguma vez em um CTA. No grupo deste estudo, encontramos um valor de $59 \%$ dos voluntários. A testagem feita por $100 \%$ dos voluntários também está relacionada a viés de seleção, visto que $88 \%$ dos sujeitos vieram de estudo realizado em ambiente hospitalar. Esse perfil difere muito do padrão de testagem encontrado na população masculina sexualmente ativa, que é de $27 \%$ (Brasil, 2008).

Quando comparado o risco de contrair HIV com a literatura (Brignol; Dourado, 2011), podemos verificar que a maior parcela dos sujeitos desta pesquisa se encontrava na mesma faixa de risco, sendo que a avaliação é de risco médio. Considerando a soma do percentil médio e alto, podemos 
entender que quase $70 \%$ deles se colocam em risco futuro. Mesmo entendendo que existem várias estratégias de prevenção, consideramos a possibilidade de eles assumirem a chance de falha dessas estratégias, independente do fator que tenha levado à falha, seja por uso de drogas psicoativas ou qualquer outro fator. A chance de falha da estratégia foi considerada pelos sujeitos ao avaliarem o risco de se infectar.

Ao pensarmos na questão da vulnerabilidade trazida pelo contexto de uso de drogas, sejam elas lícitas ou ilícitas, podemos encontrar contextos de grande risco à saúde do indivíduo. Quando somamos essas importantes questões sobre o uso de drogas às vulnerabilidades já encontradas na população HSH, temos uma ideia de potencialização dessas vulnerabilidades.

Ao falarmos de vulnerabilidade, a proposta é trazer a percepção sobre drogas e práticas sexuais que os sujeitos da pesquisa trouxeram no seu discurso. Não estamos pensado em um enfrentamento direto, no sentido da superação dessas vulnerabilidades, ou em aspectos redução de impacto. 0 objetivo é entender a percepção dos sujeitos acerca das suas práticas, visto que, como colocado por Spiassi (2011) “(...) partimos do referencial de que estar no mundo nos torna mais ou menos suscetíveis a agravos da saúde, uma vez que eventos incontroláveis acontecem a todo momento".

A ideia de comunidade LGBT é acompanhada de uma noção de liberdade, com transgressão de paradigmas e vanguardismo em relação às 
atitudes do cotidiano. O que vemos nos apontamentos deste estudo são discursos mais conservadores Por exemplo:

Detestável, inconcebível que uma pessoa utilize drogas, para se esconder dos problemas e sabendo que acabou a droga, eles vão estar lá do mesmo jeito. Aí, a pessoa vai e se droga mais e se droga mais. Enfim, não acaba. $E$, às vezes, por mais que os familiares os amigos retirem a pessoa, a pessoa volta, entendeu? Não posso te dizer se é problema de família. A meu ver, não que eu seja perfeito, a pessoa é fraca, né? A pessoa é fraca de opinião, é fraca de se gostar, é fraca de tudo. (Voluntário 013)

Horrível. Na minha opinião, eu acho que não deveria existir; acho não, com certeza. Se não existisse as pessoas, não estariam com tantos problemas assim, porque destrói a pessoa, destrói a família. Enfim, um caos. (Voluntário 021)

Ah,(silêncio) tem umas drogas que eu acho que só destroem a vida da pessoa, que só dão uma dependência, que são destrutivas. Algumas dão 
"barato" no começo, momentâneo, que, se souber levar, acaba não tendo um prejuízo na vida pessoal, fica legal, dá um "barato" só naquele momento e tal. Mas a maior parte das drogas, se você viciar, se você ficar só... Se só focar naquilo, você acaba com a sua vida, eu acho. (Voluntário 028)

Da mesma maneira que eles se colocaram liberais em relação ao uso de drogas, em outros momentos eles assumiram uma postura mais moderada ou conservadora. O mesmo aconteceu nos outros grupos de questões. Com menos visibilidade entre os conservadores, é possível identificar no mínimo dois sujeitos que se mantiveram com a postura conservadora em todos momentos da entrevista, mas o mesmo não aconteceu com os sujeitos com opiniões mais liberais. Não encontramos sujeito que apresentasse uma constante de liberalidade em suas falas. Mesmo que fizesse uso de drogas psicoativas, ele se colocava com certo grau de conservadorismo em algum ponto da entrevista.

Outro aspecto a considerar é a sociabilidade. Esse é um fator importante na construção dessa sexualidade e suas de vulnerabilidades. Antunes (2005) coloca que:

(...) bares e boates proporcionam um maior nível de socialização onde amigos se encontravam, grupos 
se reuniam e celebravam aniversários ou 'casamentos', namorados se conheciam, namorados se entravam ou se desencontravam.

A busca por esses locais de sociabilidade traz consigo a noção de espaços que podem potencializar as vulnerabilidades encontradas nessa população, na perspectiva dos componentes individuais, sociais e programáticos colocados por Ayres et al. (2003).

Sobre o uso das drogas, foi possível verificar que a maioria dos sujeitos não considerou o álcool uma droga, pois ele já se encontra tão socialmente aceito que, quando questionados sobre o uso de drogas, em nenhum momento eles entenderam que a pergunta incluía o álcool. Em contrapartida, estudos de saúde pública demonstram maior mortalidade por conta de álcool do que das outras drogas. A política do Ministério da Saúde para a atenção integral a usuários de álcool e outras drogas (2004), traz a seguinte informação:

(...) de acordo com o DATASUS, e considerando o período compreendido entre 2001 e novembro de 2003, verificamos que o maior percentual de gastos é decorrente do uso indevido de álcool - 84,5\%; contra $14,6 \%$ de gastos oriundos no consumo de outras substancias psicoativas. 
Essa indicação de gasto público com as demandas do álcool oferece clara percepção da situação dessa droga sua problemática para a saúde pública.

A percepção sobre do local de uso também é importante, assim como a rede na qual esse individuo está inserido. A rede e o espaço como fatores de sociabilidade são tratados por Antunes (2005) da seguinte maneira:
A formação de redes pode ter diferentes objetivos: de amizade, de paquera, de busca de parceiros sexuais, de trabalho etc.. O território, segundo nossa percepção, é composto por múltiplas redes relacionais, que interagem sobre si e se sobrepõem.

Com essa ótica, percebemos que os discursos se colocam geralmente de forma mais conservadora em relação ao uso de drogas em locais de sociabilidade, definidos neste trabalho como baladas.

É perigoso, eu acho que as pessoas usam muito êxtase, e... O êxtase e o ácido, eu acho que isso... Incluindo a bebida alcoólica, né? É perigoso, porque, realmente as pessoas... Eu acho que as pessoas perdem o controle. (Voluntário 006) 
Péssimo. Sim porque inibe qualquer... todas suas funções, sentidos. Você perde a noção do que é certo do que é errado. E além de ser muito arriscado, não é saudável, né? Enfim. (Voluntário 010)

Em contrapartida, alguns poucos voluntários declaram que os locais eram apropriados para o uso de drogas psicoativas.

Como eu vejo o uso de droga?! O uso de droga pode ser legal para uma pessoa, de repente, esta triste, uma pessoa que de repente não esta conseguindo se alegrar normalmente. Ai ela usa droga como recurso pra se tornar mais feliz na balada. (Voluntário 019)

Eu acho que, hoje em dia, está muito... Quase livre, assim. O pessoal consegue fácil, fica... Sei lá, fica muito louco lá muito facilmente. Mas depende da droga. Por exemplo, o êxtase que eu experimentei, não vi como uma droga muito prejudicial, assim. Só dá uma alegria, uma vontade de ficar com as pessoas, assim. Não dá um... Não tira você da sua mentalidade completa; mas se fosse, assim, um crack, maconha. 
Que você fica alucinado, você fica vendo coisas malucas. Então, assim, depende da droga pra te falar a verdade. (Voluntário 028)

Essa relação com o ambiente deixa um claro conflito, entre os usuários e não usuários de drogas. Podemos perceber que a maioria dos frequentadores discordou do uso de drogas nesses espaços, mas, ainda assim, o uso aconteceu. Os liberais e moderados passaram um entendimento de que esse é um bom local, pois é protegido e seguro. Uma das falas deixa bem clara essa sensação:

Acho ok, enfim. Acho que, óbvio, alguns momentos são exagerados para algumas pessoas, mas, ao mesmo tempo, os lugares, os clubes têm uma estrutura de também cuidar das pessoas. Bem ou mal. A maioria das pessoas não sabem disso, eles cuidam de alguma maneira para que as pessoas não tenham uma overdose o tempo inteiro. (Voluntário 032)

Em contrapartida, outros sujeitos colocaram claramente que deixaram de frequentar esses locais por conta do uso de drogas: 
Olha, muito tempo eu não vou a balada, exatamente por isso. Acaba comprometendo seu divertimento as outras pessoas usarem do seu lado. Eu acho uma coisa muito errada. A pessoa não se controla, quando usa droga. Então, eu abomino totalmente. Eu não gosto. (Voluntário 011)

Mais uma vez essa questão do espaço é ambígua. Esse espaço é ao mesmo tempo repressor e cuidadoso, repulsivo e amistoso. Isso reforça a percepção de espaço já apontada por Antunes (2005), quando coloca que "discutir os territórios de vulnerabilidade nos remete à noção de papéis sexuais, cenários e identidades", trazendo com isso um conceito de identidade de grupo e apropriação clara de espaços. Desse modo, a busca por lugares comuns e protegidos de alguma maneira se torna uma alternativa para os indivíduos que queiram fazer uso dos psicoativos e continuar seus processos de sociabilidade com os pares.

Antunes (2005) coloca as correlações do espaço para entender a vulnerabilidade ao HIV. A autora observa que, nesses espaços de sociabilidade, são constituídas subculturas de $\mathrm{HSH}$, sendo eles também usados por outros HSH que não pertencem exatamente a essas subculturas, mas fazem uso deles devido a algum tipo de identificação. Da mesma maneira, encontramos um discurso de reprovação do uso de drogas 
(ilícitas), embora eles continuassem a frequentar esses espaços, mesmo com a reprovação.

Nossa, é horrível. Porque, na balada, é o seguinte. Eu vou a baladas que as pessoas realmente utilizam drogas, mas eu só fico, eu particularmente, eu só fico, na cerveja, no whisky, na vodca, mas não, mas nunca droga né!? Eu nunca tive vontade, entendeu? (Voluntário 013)

Ao correlacionarmos drogas e sexo, podemos ver uma porcentagem grande de opiniões desfavoráveis à união das duas práticas:

Eu acho inconsequência, eu acho que é uma inconsequência da pessoa. Porque a pessoa fica fora de si. Não adianta falar que não fica, ela não consegue se controlar. Então, ela se compromete e compromete outras pessoas também. Acho que é meio irresponsabilidade. (Voluntário 011) 
O entendimento de que as drogas alteram a percepção do individuo a respeito dos riscos a que possa se expor já vem sendo apontada como uma questão importante nas discussões sobre transmissão de DST e HIV/Hepatites (Santos e Paiva, 2007; UNODOC, 2012). É possível verificar que os sujeitos entenderam ser este um fator capaz de aumentar a exposição ao HIV/Hepatites e outras DSTs.

O uso de droga no sexo, ele pode tornar o sexo da pessoa diferente. Pode fazer com que a pessoa não se previna a doenças. (Voluntário 019)

Mesmo com esse conhecimento, encontramos discursos que ultrapassaram a relação da vulnerabilidade, com uma demanda pelo prazer de forma muito mais clara e direta.

(...) depende da droga. Acho que, quando as pessoas... A gente usa cocaína, por exemplo, eu me sinto mais corajoso e saio fazendo sexo, com mais tranquilidade, sem às vezes me preocupar com prevenção, sem escolher o parceiro adequadamente. Mas eu acho que é um efeito que o álcool também causa. (Voluntário 007) 
São os prazeres da vida, né?! (risos) Tipo, unir o útil ao agradável. Muito bom. (Voluntário 012)

Acho bom. E acho que o uso de droga associado ao sexo te possibilita experimentar novas coisas que você não alcançaria no estado normal de consciência. (Voluntário 032)

Quando adicionamos um fator sexual mais específico, como a ereção, vemos uma mudança ampla de cenário. A maioria dos sujeitos achou desfavorável o uso de drogas em relação à ereção. $O$ intuito dessa pergunta foi perceber se os sujeitos que acreditassem ter ou não ereção se proporiam a ter relações sexuais. No caso de não ter ereção, a relação sexual penetrativa se daria de forma receptiva e isso aumentaria a possibilidade de uma maior exposição ao HIV e outras DSTs (Brignol; Dourado, 2007; Coleman et al., 2007; van Kesteren e Hospers; Kok, 2006).

Eu sei, pelos parceiros que eu saí, que foi até crack misturado com cocaína, maconha, ficou cheirando e cheirando, inalando aquele vapor, aquele 
gás. Infelizmente, ficou broxa totalmente, ou seja, não teve ereção nenhuma. Interfere, assim, como eu sou passivo, se o ativo fizer uso dessas drogas, interfere, sim, com certeza. (Voluntário 022)

Olha, eu já tive um namorado que usava drogas, diariamente cocaína, e as pessoas dizem: quem bebe, usa cocaína, atrapalha a ereção. Ele nunca atrapalhou a ereção. Nessa época, eu era só passivo com ele. Ele era ativo. E nós morávamos juntos. $E$ todos os dias ele se drogava, e todos os dias ele bebia até altas horas. Depois, usava cocaína para cortar o efeito da droga (álcool). É o que ele dizia para mim. Nós transávamos todos os dias, e a ereção dele era 100\%. (Voluntário 018)

Então, acontece. Quando eu fumo "um”, um "baseado" uma maconha, é... Às vezes, perde a concentração e começa a brochar, sim. Mas por falta de concentração. Mas, já a cocaína, por exemplo, ela faz... É ultra diferente. Você não tem ereção porque ela 
não deixa você ter ereção. Você fica desesperado pra ter ereção, mas não tem. (Voluntário 007)

Eu acho que ela estimula a sensibilidade do corpo, sim. E se você... (...) Aumenta o tesão, e, com isso, acaba aumentando a ereção. (...) Dizem que a “bala” (êxtase), por exemplo, não dá efeito na ereção. Pelo contrário, em mim dá. Eu acho legal. (Voluntário 006)

Ao perguntarmos sobre o uso de preservativo nas relações sexuais sob o efeito de drogas, encontramos o maior equilíbrio entre as opiniões, apesar de a maioria dos sujeitos reprovar ou não fazer uso de drogas. Isso remete a um imaginário geral de que usar drogas leva as pessoas a perder completamente a noção dos seus atos, ficando abertas a todo tipo de práticas desprotegidas. Essa percepção geral aparece nas entrevistas, mas não de forma unânime.

Eu acho que não, acho que as drogas... Acho que o momento, acho que a pessoa esquece. Acho que, sei lá, a droga deixa... Vamos dizer... Acho que você, usando a droga, você esquece, você não lembra 
de usar preservativo. No meu ponto de vista, né. Eu nunca usei droga, mas a gente vê muito aí em balada, que as pessoas saem e não se preocupam. Poucos se preocupam com o uso de preservativo após o uso de drogas. (Voluntário 004)

Eu tenho perfeita clareza de usar. Eu acho que, de forma geral, é o mesmo que acontece com a bebida. As pessoas têm vontade de determinadas coisas, dentre elas pode ser não usar camisinha, e a hora que usa substâncias que alteram, vão no embalo." (Voluntário 030)

A estratégia de prevenção mais citada foi o uso do preservativo. A negociação do uso de preservativo é acompanhada de outros múltiplos fatores, os quais vão além da relação racional da preservação. Por exemplo, o desejo pode ser um fator determinante muito mais forte para o não uso do preservativo do que estar sob efeito de drogas psicoativas.

Sim, em geral, mas é muito fácil de eu perder, se eu não tiver uma mão, por exemplo, ou se o parceiro 
for alguém que me interessa muito, e sugerir que não use. Pode ser que eu não use. (Voluntário 003)

Entender como se dá essa relação entre drogas e o comportamento sexual nessa população nos direciona de forma mais clara para como conduzir políticas públicas de prevenção de HIV/Hepatites/DSTs, bem como para ter um melhor substrato para trabalhar estratégias de redução de danos.

A redução de danos em relação ao uso de drogas é uma estratégia que consegue os melhores resultados, no sentido de empoderamento do indivíduo sobre suas práticas e suas escolhas (Brasil, 2004). A somatória desses fatores nos ajuda a minimizar os efeitos de vulnerabilidade que se encontram nessa população, avaliando estratégias e propondo intervenções que, de alguma maneira, tornem esse sujeito um cidadão de fato.

\section{Limitações do estudo}

Identificamos como uma das limitações do estudo o número de participantes $(n=34)$ e sua representatividade em relação à população estudada (análises mais consistentes). Há presença clara e marcante de um viés de seleção. Outro ponto que pode ser apontado como limitante foi a 
escolha da estratégia de recrutamento. A técnica de bola de neve nos leva a subgrupos muito específicos, aumentando muito a sensação do viés. Em contrapartida, a escolha da técnica nos permitiu um esgotamento dos discursos nos principais locais de recrutamento dos sujeitos deste estudo, dando uma visão mais aprofundada nos dados qualitativos, e fazendo uma combinação de estudos qualitativos e quantitativos. Outra limitação do presente estudo foi a duração das entrevistas. Os tempos curtos de fala podem ter dado pouca oportunidade para os sujeitos expressarem com maior clareza e desenvoltura suas percepções sobre os temas. Essa questão só foi percebida quando ocorreu o processamento das entrevistas. Para contornar esse problema, o uso da técnica de análise de conteúdo (Bardin, 2011) foi de suma importância para minimizar o impacto da extensão do discurso. 


\section{Conclusão}

Com os dados obtidos neste estudo, concluímos ser possível entender que o uso de drogas psicoativas aumenta a vulnerabilidade dessa população de modo a influenciar suas práticas de prevenção em relação ao HIV e outras DSTs.

Identificamos ainda que existe um consumo de drogas psicoativas em mais de $90 \%$ dos sujeitos em estudo. Esse consumo se limita basicamente ao uso de álcool, entres as drogas psicoativas licitas, e da maconha, dentre as drogas psicoativas ilícitas.

Sobre as práticas sexuais, elas se dão com múltiplos parceiros e o não uso de preservativo, e, mais fortemente, o uso intermitente de preservativo está marcadamente presente no grupo.

O relato da percepção sobre o uso de drogas psicoativas transita entre posições conservadoras e liberais, sendo que o maior número de relatos se reúne no espectro mais conservador das falas. Ao colocarmos que existe uma transição nas falas, essa transição é marcada mais fortemente entre os que apresentaram opiniões mais liberais. Os que se colocaram com opiniões mais conservadoras desde as primeiras falas tenderam a continuar com a mesma opinião sobre o uso de drogas psicoativas e práticas sexuais.

Estudos de maior abrangência e profundidade são necessários para maior entendimento de tais práticas nessa população. 


\section{Considerações finais}

Estudos mais aprofundados e em maior escala nos darão mais opções para traçar planos de ação. Um bom exemplo encontrado na caminhada dessa dissertação foi um site sobre saúde do governo Sul Australiano (http://www.dassa.sa.gov.au/site/page.cfm?u=477), voltado inteiramente para o uso de drogas, como o OBID no Brasil, e onde se pode responder o Assist de forma anônima. No final do questionário, aparece a sua pontuação e uma sugestão de ação. Apesar de não sabermos como funciona exatamente, podemos supor que, além desse retorno, ele gere um banco de dados que poderá ser usado pelo governo para traçar estratégias e ações paras as mais diversas populações. Esse é um bom exemplo a ser seguido para conseguirmos maior substrato teórico na busca de ações programáticas que visem à diminuição das vulnerabilidades em diversas populações. 
Anexos 
Anexo A - Carta de aprovação da Comissão de Ética para Análise de Projetos de Pesquisa do HC-FMUSP 


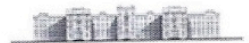 MEDICINA \\ TSP \\ COMITÊ DE ÉTICA EM PESQUISA}

\section{APROVAÇÃO}

O Comitê de Ética em Pesquisa da Faculdade de Medicina da Universidade de São Paulo, em sessão de 23/11/2011, APROVOU o Protocolo de Pesquisa $\mathrm{n}^{\circ}$ 458/11 intitulado: "COMPORTAMENTO DE RISCO DE TRANSMISSÃO DO HIV EM UMA POPULAÇÃO DE HSH QUE FAZ USO DE MDMA E OUTRAS DROGAS PSICOATIVAS" apresentado pelo Departamento de MEDICINA PREVENTIVA

Cabe ao pesquisador elaborar e apresentar ao CEPFMUSP, os relatórios parciais e final sobre a pesquisa (Resolução do Conselho Nacional de Saúde no 196, de 10/10/1996, inciso IX.2, letra "c").

Pesquisador (a) Responsável: Heráclito Barbosa de Carvalho Pesquisador (a) Executante: Augusto Mathias

CEP-FMUSP, 25 de Novembro de 2011.

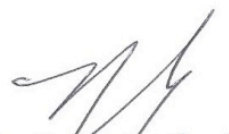

Prof. Dr. Paulo Eurpedes Marchiori

Vice-Coordenador interino

Comitê de Ética em Pesquisa

Comitê de Ética em Pesquisa da Faculdade de Medicina e-mail: cep.fmusp@hcnet.usp.br 
Anexo B - Termo de confidencialidade aplicado aos voluntários antes do início das entrevistas 
FACUldade de medicina da Universidade de são paulo

\section{MODELO DE TERMO DE CONSENTIMENTO LIVRE E ESCLARECIDO}

\section{DADOS DE IDENTIFICAÇÃO DO SUJEITO DA PESQUISA OU RESPONSÁVEL LEGAL}

1. NOME:

DOCUMENTO DE IDENTIDADE N :

SEXO : .M $\square \quad F$

DATA NASCIMENTO: ........................

ENDEREÇO $\mathrm{N}^{\circ}$ APTO:

BAIRRO:

CEP: TELEFONE: DDD ( CIDADE: SEXO: $M \square \quad F \square$

DOCUMENTO DE IDENTIDADE :. $\mathrm{N}^{\circ}$ APTO:

ENDEREÇO:

BAIRRO: CIDADE:

CEP: TELEFONE: DDD .)

\section{DADOS SOBRE A PESQUISA}

1. TÍTULO DO PROTOCOLO DE PESQUISA: Comportamento de risco de transmissão do HIV em uma população de HSH que faz uso de MDMA e outras drogas psicoativas

2. PESQUISADOR : Heráclito Barbosa de Carvalho.

CARGO/FUNÇÃO: Professor Doutor. INSCRIÇÃO CONSELHO REGIONAL N CRM: 44785 PESQUISADOR EXECUTOR: Augusto Mathias

UNIDADE DO HCFMUSP: Departamento de Medicina Preventiva

3. AVALIAÇÃO DO RISCO DA PESQUISA:

\begin{tabular}{|l|l|l|l|} 
RISCO MÍNIMO & $X$ & \multicolumn{1}{l}{ RISCO MÉDIO } & \\
RISCO BAIXO & RISCO MAIOR & \\
& &
\end{tabular}

4.DURAÇÃO DA PESQUISA : 2 anos 


\section{FACUldade de medicina da UNiversidade de são paulo}

1 - Este estudo pretende compreender os comportamentos individuais, associados a risco de infecção pelo HIV quando influenciado pelo uso de algumas drogas.

2 - Procedimentos: Aplicação de um questionário, sobre o uso de álcool e drogas e práticas sexuais. Essas informações serão de caráter confidencial, garantindo anonimato e sigilo pessoal quanto às informações fornecidas.

3 - Riscos: O desconforto por responder perguntas muito pessoais;

4 - Benefícios: Você não terá nenhum beneficio direto na participação desse estudo. Essas informações irão contribuir para o aprofundamento sobre os conhecimentos nessa área;

5 - Compensação: Todas as atividades relacionadas à pesquisa serão gratuitas, sem nenhum tipo de compensação financeira;

6 - Você pode conversar com a equipe da pesquisa sobre qualquer dúvida ou preocupação que tiver a respeito deste estudo. O pesquisador responsável por este estudo é o Dr. Heráclito Barbosa de Carvalho no telefone (11) 30617074, no seguinte endereço: Av. Dr Arnaldo, 455, $2^{\circ}$. Andar - Departamento de Medicina Preventiva da FMUSP., CEP 01246-903.

Você tem direito de ser mantido atualizado sobre os resultados parciais das pesquisas, se disponíveis, ou de resultados relevantes para o estudo que sejam do conhecimento dos pesquisadores.

Se você tiver alguma consideração ou dúvida sobre a ética da pesquisa, entre em contato com o Comitê de Ética em Pesquisa (CEP) -Av. Dr. Arnaldo, 455 - Instituto Oscar Freire - $1^{\circ}$ andar- tel: 3061-8004, FAX: 3061-8004-E-mail: cep.fmusp@hcnet.usp.br

7 - É garantida a liberdade da retirada de consentimento a qualquer momento e deixar de participar do estudo, sem qualquer prejuízo à continuidade de seu tratamento na Instituição; 8 - Suas informações serão guardadas com a máxima confidencialidade. Indivíduos e organizações que poderão ter acesso aos dados das respostas das questões do estudo terão que pedir permissão ao Comissão de Ética para Análise de Projeto de Pesquisa - CAPPesq da Universidade de Medicina da USP.

9 Danos: A sua participação neste estudo pode incluir perda de privacidade, mas suas informações serão guardadas com a máxima confidencialidade. Nós faremos todo o possível para assegurar que as informações pessoais registradas em seu questionário sejam mantidas privadas; suas respostas às perguntas vão ser manejados com o máximo de privacidade. Seu nome não vai aparecer nos questionários que você responder ficará registrado somente suas iniciais. Nós não podemos, porém, garantir total privacidade. Suas informações pessoais serão fornecidas se requerido por lei. Se as informações deste estudo forem publicadas ou apresentadas em encontros científicos, seu nome e outras informações pessoais não serão usadas. Seu nome não aparecerá em nenhum relatório publicado sobre os resultados desta pesquisa.

\section{CONSENTIMENTO PARA CONTATOS FUTUROS}

Poderá também ser perguntado a você no futuro se você deseja participar voluntariamente em pesquisas adicionais. Para isso precisaremos que você nos autorize a entrar em contato. Por favor, leia a afirmação a seguir cuidadosamente e marque SIM ou NÃO, de acordo com a opção que melhor expressa a sua opinião. Independente do que você decidir, sua decisão não afetará seus cuidados de saúde nem a sua participação neste estudo.

"Alguém poderá entrar em contato comigo no futuro para perguntar se eu quero participar de outra pesquisa."

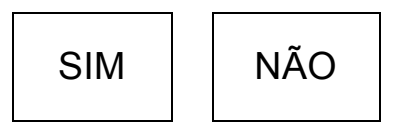


Acredito ter sido suficientemente informado a respeito das informações que li ou que foram lidas para mim, descrevendo a pesquisa "Comportamento de risco de transmissão do HIV em uma população de HSH que faz uso de MDMA e outras drogas psicoativas". Eu discuti com o pesquisador executor sobre a minha decisão em participar nesse estudo. Ficaram claros para mim quais são os propósitos do estudo, os procedimentos a serem realizados, seus desconfortos e riscos, as garantias de confidencialidade e de esclarecimentos permanentes. Ficou claro também que minha participação é isenta de despesas. Concordo voluntariamente em participar deste estudo e poderei retirar o meu consentimento a qualquer momento, antes ou durante o mesmo, sem penalidades ou prejuízo ou perda de qualquer benefício que eu possa ter adquirido.

Assinatura do paciente/representante legal Data

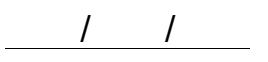

Assinatura da testemunha

Data 11

para casos de pacientes menores de 18 anos, analfabetos, semi-analfabetos ou portadores de deficiência auditiva ou visual.

(Somente para o responsável do projeto)

Declaro que obtive de forma apropriada e voluntária o Consentimento Livre e Esclarecido deste paciente ou representante legal para a participação neste estudo. 
Anexo C - Questionário aplicado aos sujeitos deste estudo 


\section{Questionário de comportamento sexual e uso de êxtase e outras drogas}

ID:

\section{Bloco A - Características Sócio-Demográficas}

$\mathbf{1}^{\mathrm{A}}$. Qual sua data de nascimento?

$2^{A}$. Estado civil

$\begin{array}{ll}\text { Solteiro } & \text { (1) } \\ \text { Casado } & \text { (2) } \\ \text { Separado - divorciado } & \text { (3) } \\ \text { Concubinato (amasiamento) } & \text { (4) } \\ \text { Outro\# } & \text { (5) }\end{array}$

\# Especifique

$3^{\mathbf{A}}$. Raça / Etnia

$\begin{array}{ll}\text { Branco } & \text { (1) } \\ \text { Mulato/pardo } & \text { (2) } \\ \text { Negro } & \text { (3) } \\ \text { Amarelo } & \text { (4) } \\ \text { Indígena (brasileiro nativo) } & \text { (5) } \\ \text { NDA } & \text { (6) } \\ \text { NR } & \text { (7) }\end{array}$

$4^{A}$. Posse de itens (CCEB)

\begin{tabular}{|c|c|c|c|c|c|}
\hline & \multicolumn{5}{|c|}{ Quantidades de itens } \\
\hline & 0 & 1 & 2 & 3 & 4 ou + \\
\hline Televisão em cores & 0 & 1 & 2 & 3 & 4 \\
\hline Rádio & 0 & 1 & 2 & 3 & 4 \\
\hline Banheiro & 0 & 4 & 5 & 6 & 7 \\
\hline Automóvel & 0 & 4 & 7 & 9 & 9 \\
\hline Empregada Mensalista & 0 & 3 & 4 & 4 & 4 \\
\hline Máquina de lavar & 0 & 2 & 2 & 2 & 2 \\
\hline Videocassete e/ou DVD & 0 & 2 & 2 & 2 & 2 \\
\hline Geladeira & 0 & 4 & 4 & 4 & 4 \\
\hline Freezer( Aparelho independente ou parte da geladeira duplex) & 0 & 2 & 2 & 2 & 2 \\
\hline
\end{tabular}


$\mathbf{5}^{\mathbf{A}}$.Grau de instrução do chefe de família (CCEB)

\begin{tabular}{|l|l|l|}
\hline Analfabeto/Primário incompleto & Analfabeto/ Até $3^{\text {a }}$ Série Fundamental & 0 \\
\hline Primário Completo/ Ginasial Incompleto & Até $4^{\text {a Série Fundamental }}$ & 1 \\
\hline Ginasial completo/ Colegial incompleto & Fundamental Completo & 2 \\
\hline Colegial completo/ Superior incompleto & Médio Completo & 4 \\
\hline Superior completo & Superior Completo & 8 \\
\hline
\end{tabular}

6$^{\text {A }}$.Qual seu Grau de instrução?

\begin{tabular}{|l|l|l|}
\hline Analfabeto/Primário incompleto & Analfabeto/ Até $3^{\text {a }}$ Série Fundamental & 0 \\
\hline Primário Completo/ Ginasial Incompleto & Até $4^{\text {a Série Fundamental }}$ & 1 \\
\hline Ginasial completo/ Colegial incompleto & Fundamental Completo & 2 \\
\hline Colegial completo/ Superior incompleto & Médio Completo & 3 \\
\hline Superior completo & Superior Completo & 4 \\
\hline
\end{tabular}


Bloco B - Consumo de Êxtase

$1^{B}$. Você usou êxtase nos últimos quinze dias?
$\operatorname{Sim}$ (1)
Não (2) $\rightarrow$ Bloco $C^{D}$

$2^{\text {B }}$. Quantos comprimidos você consumiu?

$3^{\text {B }}$. Quais motivos levaram você a consumir êxtase na ultima vez? (pode escolher várias resposta)

$\begin{array}{ll}\text { Curiosidade } & \text { (1) } \\ \text { Porque meu(s) amigo(s)/parceiro(s) usam } & \text { (2) } \\ \text { O êxtase é mais fácil de se conseguir } & \text { (3) } \\ \text { O êxtase é mais fácil de usar } & \text { (5) } \\ \text { Porque sempre uso } & \text { (6) } \\ \text { Nenhum motivo especial } & \text { (7) } \\ \text { Porque é legal } & \text { (8) }\end{array}$

\# Especifique

$4^{\mathrm{B}}$. Qual o local onde você usou (onde deu o barato) êxtase na ultima vez? (escolher uma única resposta)

Na rua, praça, becos (1)

Em bares, boates, festas

$\mathrm{Na}$ sua casa, em casa de (3) amigo/namorado(a)

Sauna, sexclub, casas de swing (4)

Outro\#

\# Especifique

$5^{\mathrm{B}}$. Quando você usou êxtase da ultima vez, que bebidas você tomou?

\begin{tabular}{lll} 
Álcool & Não (1) & Sim(2) \\
\hline Sucos & Não (1) & Sim(2) \\
\hline Refrigerantes & Não (1) & Sim (2) \\
\hline Água & Não (1) & Sim(2) \\
Outras* $^{*}$ & Não (1) & Sim(2)
\end{tabular}

${ }^{*}$ Quais: 
$6^{\text {B }}$. Quando você consumiu êxtase você tem consumiu outras drogas junto? (perguntar droga por droga)

Sim (1)

Não (2) $\rightarrow Q 7^{B}$

\begin{tabular}{|c|c|c|c|c|}
\hline & Uso & Antes & Durante & Depois \\
\hline Tabaco & $\mathrm{N}$ (1) & & & \\
\hline Maconha & $N$ (1) & & & \\
\hline Cocaína & $N$ (1) & & & \\
\hline Mesclado* & $\mathrm{N}$ (1) & & & \\
\hline Inalantes & $N$ (1) & & & \\
\hline Opiáceos ${ }^{* *}$ & $N$ (1) & & & \\
\hline Heroína & $N$ (1) & & & \\
\hline Alucinógenos & $N$ (1) & & & \\
\hline Tranquilizantes. ${ }^{* * *}$ & $\mathrm{~N}$ (1) & & & \\
\hline Anfetaminas & $\mathrm{N}$ (1) & & & \\
\hline Outra\# & $\mathrm{N}$ (1) & & & \\
\hline
\end{tabular}

* Crack fumada no cigarro de tabaco ou de maconha

** ópio, codeína, elixir paregórico, algafan, morfina, demerol, dolantina

*** benzodiazepínico, gardenal

\# Especifique

$7^{\mathrm{B}}$. Quando você uso êxtase da ultima vez, você fez sexo?

$\operatorname{Sim}$ (1)

Não (2) $\rightarrow$ Bloco C

$\mathbf{8}^{\mathbf{B}}$. Com quem você fez sexo depois que consumiu êxtase da ultima vez?

Homem
Mulher
Ninguém

$9^{B}$. Que posição sexual você adotou nessa ocasião

(pode escolher várias resposta) Uso de Camisinha

\begin{tabular}{ll|l|l|l|} 
& \multicolumn{5}{c}{ Sempre Às vezes } & Nunca \\
\cline { 5 - 6 } Insertivo (ativo) & (1) & & & \\
\hline Receptivo (passivo) & (2) & & & \\
Insertivo e Receptivo (versátil) & (3) & & & \\
\hline Oral receptivo (fez) & (4) & & & \\
Oral insertivo (recebeu) & (5) & & & \\
Vaginal & (6) & & & \\
\cline { 5 - 6 } & & & &
\end{tabular}


$1^{\mathrm{C}}$. Na sua vida qual(is) dessa(s) Não Sim substâncias você já usou?
a. derivados do tabaco

$0 \quad 3$
b. bebidas alcoólicas

$0 \quad 3$
c. maconha

$0 \quad 3$
d. cocaina, crack

$0 \quad 3$
e. anfetaminas ou êxtase

$0 \quad 3$
f. inalantes

$0 \quad 3$
g. hipnóticos/sedativos

$0 \quad 3$
h. alucinóginos

$0 \quad 3$
i. opióides

$0 \quad 3$
j. outras, especificar

$0 \quad 3$

- Se "Não" em todos os itens investigue: Nem mesmo na escola?

- Se "Não" em todos os itens, pare a entrevista.

- Se "Sim" para alguma droga, continue com as demais questões.

$2^{C}$. Durante os três últimos meses, com que freqüência, você utilizou essa(s) substância(s) me mencionou (primeira droga, depois a segunda, etc)

\begin{tabular}{|c|c|c|c|c|}
\hline $\begin{array}{l}\text { J } \\
\stackrel{5}{5} \\
\text { L }\end{array}$ & 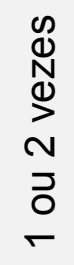 & 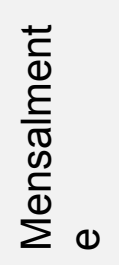 & 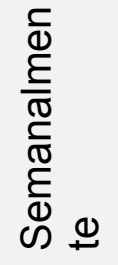 & 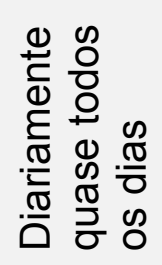 \\
\hline 0 & 2 & 3 & 4 & 6 \\
\hline 0 & 2 & 3 & 4 & 6 \\
\hline 0 & 2 & 3 & 4 & 6 \\
\hline 0 & 2 & 3 & 4 & 6 \\
\hline 0 & 2 & 3 & 4 & 6 \\
\hline 0 & 2 & 3 & 4 & 6 \\
\hline 0 & 2 & 3 & 4 & 6 \\
\hline 0 & 2 & 3 & 4 & 6 \\
\hline 0 & 2 & 3 & 4 & 6 \\
\hline 0 & 2 & 3 & 4 & 6 \\
\hline
\end{tabular}

- Se, "Nunca" em todos os itens da questão 2 pule para questão 6 , com outras respostas continue com as demais questões. 
$3^{\mathrm{C}}$. Durante os três últimos meses, com que freqüência você teve um forte desejo ou urgência em consumir? (primeira droga, segundadroga, etc)

\begin{tabular}{ll}
\hline a. derivados do tabaco \\
\hline b. bebidas alcoólicas \\
\hline c. maconha & 0 \\
\hline d. cocaina, crack & 0 \\
\hline e. anfetaminas ou êxtase & 0 \\
\hline f. inalantes & 0 \\
\hline g. hipnóticos/sedativos & 0 \\
\hline h. alucinóginos & 0 \\
i. opióides & 0 \\
j. outras, especificar & 0
\end{tabular}

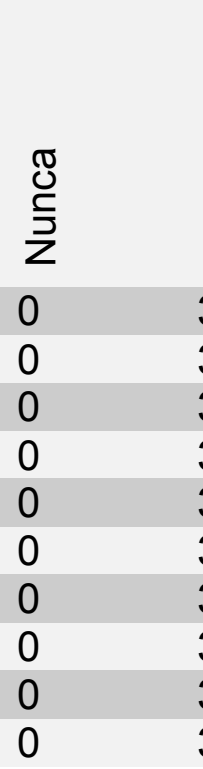

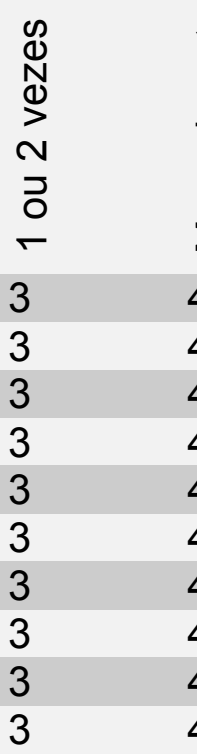

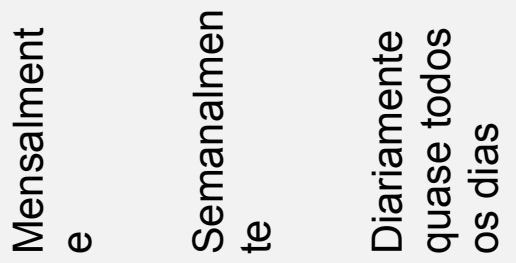

$4^{\mathrm{C}}$. Durante os três últimos meses com que freqüência o seu consumo de (primeira droga, depois a segunda droga, etc) resultou em problema de saúde, social, legal ou financeiro?

\begin{tabular}{|c|c|c|c|c|c|}
\hline $\begin{array}{l}\text { Durante os très últimos } \\
\text { ses com que freqüência o } \\
\text { d consumo de (primeira } \\
\text { ga, depois a segunda droga, } \\
\text { ) resultou em problema de } \\
\text { ide, social, legal ou } \\
\text { anceiro? }\end{array}$ & $\begin{array}{l}\text { J } \\
\text { Е } \\
\Sigma\end{array}$ & 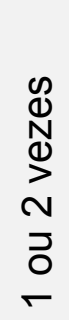 & 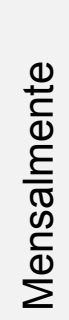 & 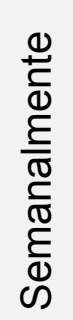 & 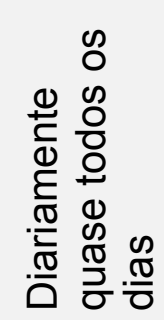 \\
\hline a. derivados do tabaco & 0 & 4 & 5 & 6 & 7 \\
\hline b. bebidas alcoólicas & 0 & 4 & 5 & 6 & 7 \\
\hline c. maconha & 0 & 4 & 5 & 6 & 7 \\
\hline d. cocaina, crack & 0 & 4 & 5 & 6 & 7 \\
\hline e. anfetaminas ou êxtase & 0 & 4 & 5 & 6 & 7 \\
\hline f. inalantes & 0 & 4 & 5 & 6 & 7 \\
\hline g. hipnóticos/sedativos & 0 & 4 & 5 & 6 & 7 \\
\hline h. alucinóginos & 0 & 4 & 5 & 6 & 7 \\
\hline i. opióides & 0 & 4 & 5 & 6 & 7 \\
\hline j. outras, especificar & 0 & 4 & 5 & 6 & 7 \\
\hline
\end{tabular}


$5^{\mathrm{C}}$. Durante os três últimos meses com que freqüência por causa do seu uso de (primeira droga, depois a segunda droga, etc), você deixou de fazer coisas que eram normalmente esperadas de você?

$\begin{array}{llllll}\text { a. derivados do tabaco } & 0 & 5 & 6 & 7 & 8 \\ \text { b. bebidas alcoólicas } & 0 & 5 & 6 & 7 & 8 \\ \text { c. maconha } & 0 & 5 & 6 & 7 & 8 \\ \text { d. cocaina, crack } & 0 & 5 & 6 & 7 & 8 \\ \text { e. anfetaminas ou êxtase } & 0 & 5 & 6 & 7 & 8 \\ \text { f. inalantes } & 0 & 5 & 6 & 7 & 8 \\ \text { g. hipnóticos/sedativos } & 0 & 5 & 6 & 7 & 8 \\ \text { h. alucinóginos } & 0 & 5 & 6 & 7 & 8 \\ \text { i. opióides } & 0 & 5 & 6 & 7 & 8 \\ \text { j. outras, especificar } & 0 & 5 & 6 & 7 & 8\end{array}$

- Faça as questões 6 e 7 para todas as substâncias mencionadas na questão 1.

$6^{\mathrm{C}}$. Há amigos, parentes ou outra pessoa que tenha demonstrado preocupação com seu uso de (primeira droga, depois a segunda droga, etc...)?
a. derivados do tabaco
b. bebidas alcoólicas

$0 \quad 6$
c. maconha
d. cocaina, crack
0
e. anfetaminas ou êxtase
f. inalantes
g. hipnóticos/sedativos

63
6
6
0
h. alucinóginos
i. opióides
j. outras, especificar
6
6
0
6
6
6

$0 \quad 6$
6
0
6

3
3
3
3
3
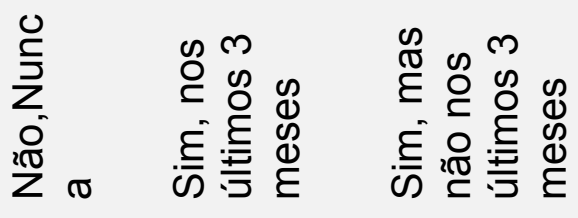
$7^{\mathrm{C}}$. Alguma vez você já tentou controlar, diminuir ou parar o uso de ((primeira droga, depois a segunda droga, etc...) e não conseguiu?
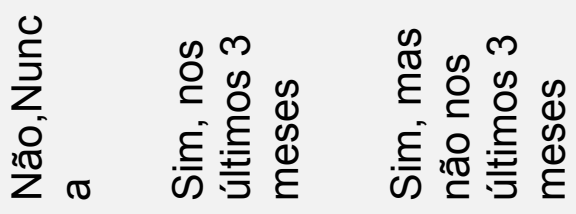

k. derivados do tabaco

0

\section{6}

I. bebidas alcoólicas

m. maconha

n. cocaina, crack 0

0

o. anfetaminas ou êxtase

0

p. inalantes

0

q. hipnóticos/sedativos

0

r. alucinóginos

0

s. opióides

0

t. outras, especificar

0

0

6

3

$6 \quad 3$

63

$6 \quad 3$

$6 \quad 3$

$6 \quad 3$

63

$6 \quad 3$

$6 \quad 3$

63

$\mathbf{8}^{\mathrm{C}}$. Alguma vez você já usou drogas por injeção (Apenas uso não médico) Não, Nunca Sim, nos últimos $3 \quad$ Sim, mas não nos meses últimos 3 meses 
Bloco D - Uso de êxtase uma vez na vida

$1^{\mathrm{D}}$. Você já usou êxtase alguma vez na vida?

Sim (1) Não (2) $\rightarrow$ Bloco E

$2^{\mathrm{D}}$. Quantos comprimidos você consumiu?

$3^{\text {D }}$. Quais motivos levaram você a consumir o êxtase? (pode escolher várias resposta)

Curiosidade
Porque meu(s) amigo(s)/parceiro(s) usam
O êxtase é mais fácil de se conseguir
O êxtase é mais fácil de usar
Porque sempre uso

\# Especifique

$4^{\mathrm{D}}$. Quais os locais onde você usou êxtase (onde dá o barato)? (pode escolher mais de uma resposta)

Na rua, praça, becos

Em bares, boates, festas

$\mathrm{Na}$ sua casa, em casa de (3)

amigo/namorado(a)

Sauna, sexclub, casas de swing

Outro\#

\# Especifique

$5^{\text {D }}$. Como você obteve o êxtase?

(pode dar mais de uma resposta)

Compra de traficante

(1) Ganha do parceiro/amigo

Ganha de traficante

Troca por outras "mercadorias"

Compra do parceiro/amigo

Troca por sexo *

${ }^{*}$ Caso você não tenha mencionado troca por sexo: $\mathbf{Q} \mathbf{8}^{\mathbf{D}}$

$6^{\mathrm{D}}$. Com que freqüência você se utiliza do sexo para obter o êxtase?

$\begin{array}{ll}\text { Sempre } & \text { (1) } \\ \text { Quase sempre } & \text { (2) } \\ \text { Às vezes } & \text { (3) } \\ \text { Quase nunca } & \text { (4) } \\ \text { Não se aplica } & \text { (5) }\end{array}$


$7^{\mathrm{D}}$. O uso de êxtase mudou a freqüência de suas relações sexuais na ocasião?

$\begin{array}{ll}\text { Aumentou } & \text { (1) } \\ \text { Diminuiu } & \text { (2) } \\ \text { Não mudou } & \text { (3) } \\ \text { Não se aplica } & \text { (5) }\end{array}$

$8^{\text {D. }}$ Quando você usou êxtase da ultima vez e fez sexo, você usou camisinha?

$\begin{array}{ll}\text { Sim } & \text { (1) } \\ \text { Não } & \text { (2) } \\ \text { Não me lembro } & \text { (3) }\end{array}$

$9^{\text {D }}$ Quando você consumiu êxtase você também consumiu outras drogas junto? (perguntar droga por droga)
Sim (1) Quais?
Não (2) $\rightarrow Q \mathbf{Q} 10^{\mathrm{D}}$

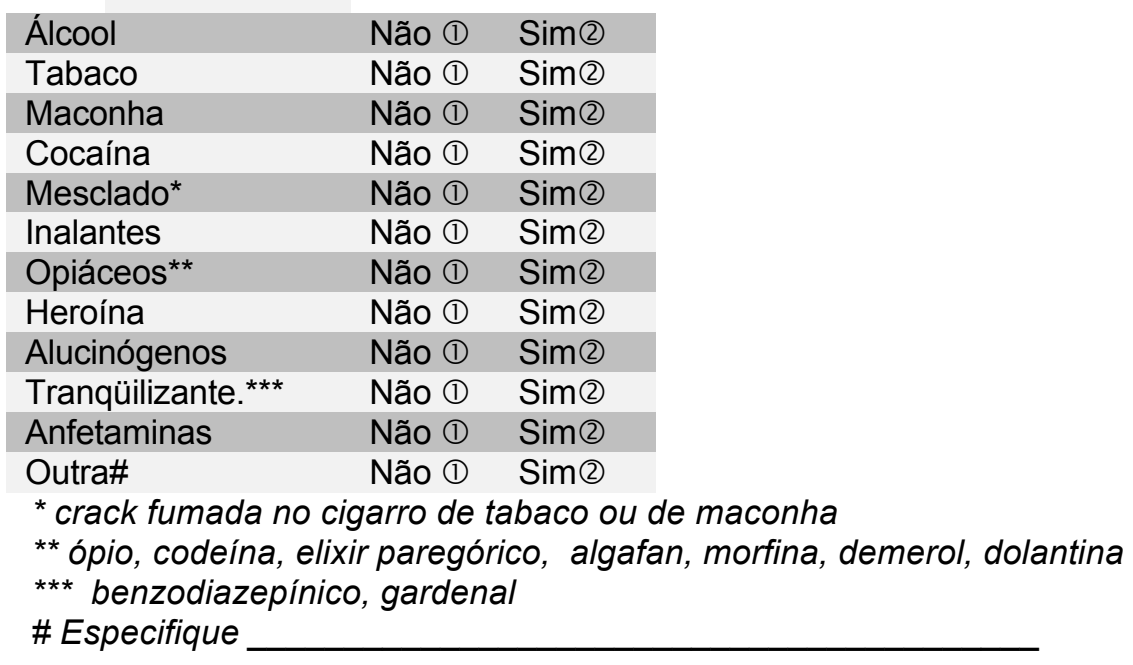

$10^{\mathrm{D}}$. Depois que você usou o êxtase da ultima vez, como ficou seu consumo de:

Obs. A alternativa "não mudou" vale para quem usa a droga (perguntar droga por droga)

\begin{tabular}{|c|c|c|c|c|c|}
\hline & NÃO USA & Não mudou & $\uparrow$ & $\downarrow$ & Parou \\
\hline Álcool & $N$ (1) & (2) & (3) & (4) & (5) \\
\hline Tabaco & $N(1)$ & (2) & (3) & (4) & (5) \\
\hline Maconha & $N$ (1) & (2) & (3) & (4) & (5) \\
\hline Cocaína & $N$ (1) & (2) & (3) & (4) & (5) \\
\hline Mesclado* & $N$ (1) & (2) & (3) & (4) & (5) \\
\hline Inalantes & $N$ (1) & (2) & (3) & (4) & (5) \\
\hline Opiáceos** & $N$ (1) & (2) & (3) & (4) & (5) \\
\hline Heroína & $N$ (1) & (2) & (3) & (4) & (5) \\
\hline Alucinógenos & $N$ (1) & (2) & (3) & (4) & (5) \\
\hline Tranqüilizantes ${ }^{* * *}$ & $N$ (1) & (2) & (3) & (4) & (5) \\
\hline Anfetaminas & $N(1)$ & (2) & (3) & (4) & (5) \\
\hline Outra\# & $N$ (1) & (2) & (3) & (4) & (5) \\
\hline
\end{tabular}

* Crack fumada no cigarro de tabaco ou de maconha

** ópio, codeína, elixir paregórico, algafan, morfina, demerol, dolantina

*** benzodiazepínico, gardenal

\# Especifique 


\section{BIoco E - PRÁTICAS DE RISCORELACIONADAS AO COMPORTAMENTO SEXUAL}

$1^{\mathrm{E}}$. Você já teve alguma relação sexual na sua vida (Considerar praticas de sexo anal, vaginal e oral)?

$$
\operatorname{Sim}(1) \quad \text { Não (2) Bloco F }
$$

$2^{\mathrm{E}}$. Com quantas pessoas no ultimo mês você manteve relações sexuais?

$3^{\mathrm{E}}$. Qual a sua freqüência de relações sexuais num mês típico?

\begin{tabular}{|llll|} 
Menos de $1 \mathrm{x}$ mês & (1) & Finais de semana & (4) \\
\hline Até $3 \mathrm{x}$ por mês & (2) & 3 a 6 x semana & (5) \\
\hline 1 a $2 x$ semana & (3) & Diariamente & (6)
\end{tabular}

$4^{\mathrm{E}}$. Com que freqüência você usa camisinha ao manter relações sexuais (Considerar praticas de sexo anal, vaginal e oral)?

$\begin{array}{ll}\text { Sempre } & \text { (1) } \\ \text { Quase sempre } & \text { (2) } \\ \text { Âs vezes } & \text { (4) } \\ \text { Quase nunca } & \text { (5) } \\ \text { Nunca } & \text { (6) } \\ \text { Não tem relação sexual }\end{array}$

$5^{\mathrm{E}}$. Você alguma vez recebeu de alguma pessoa: presente, dinheiro, bens ou drogas em troca de relação sexual?

$$
\text { Sim (1) Não (2) } \rightarrow \mathbf{Q}^{\mathbf{9}}
$$

$6^{\mathrm{E}}$ Isto acontece:

$\begin{array}{ll}\text { Sempre } & \text { (1) } \\ \text { Quase sempre } & \text { (2) } \\ \text { Às vezes } & \text { (3) } \\ \text { Quase nunca } & \text { (4) }\end{array}$

$7^{\mathrm{E}}$. Nesta situação você usa camisinha?

\begin{tabular}{ll} 
Sempre & (1) \\
Quase sempre & (2) \\
\hline Às vezes & (3) \\
Quase nunca & (4) \\
Nunca & (5) \\
\hline
\end{tabular}

$\mathbf{8}^{\mathrm{E}}$. Você se preocupou com a AIDS?

$$
\text { Sim (1) Não (2) }
$$

$\mathbf{9}^{\mathrm{E}}$. Você alguma vez teve relação sexual com mulheres no ultimo mês?
Sim (1)
Não
(2) $\rightarrow Q 12^{D}$ 
$10^{\mathrm{E}}$. Isso fez com que você modificasse seu comportamento em relação:

a) Ao uso de drogas?

Sim (1) Não (2)

b) Ás práticas sexuais?
Sim
Não (2)

$11^{\mathrm{E}}$. Você se preocupou com a AIDS quando fez sexo com mulheres?
Sim (1)
Não
(2)

$12^{\mathrm{E}}$. No ultimo mês você fez sexo com quantas pessoas?

Homem Quantos
Mulher
Ninguém

$13^{\mathrm{E}}$. Que posição sexual você adotou quando fez sexo da ultima vez?

(pode escolher várias resposta) Uso de Camisinha

\begin{tabular}{ll|l|l|l|} 
& \multicolumn{5}{c}{ Sempre Às vezes } & Nunca \\
\cline { 5 - 5 } Insertivo (ativo) & (1) & & & \\
\hline Receptivo (passivo) & (2) & & & \\
Insertivo e Receptivo (versátil) & (3) & & & \\
\hline Oral receptivo (fez) & (4) & & & \\
Oral insertivo (recebeu) & (5) & & & \\
\hline Vaginal & (6) & & & \\
\cline { 5 - 6 } & & &
\end{tabular}




\section{Bloco F - Mudanças de Comportamentos e Testagem de HIV}

$1^{\mathrm{F}}$. Nos últimos 12 meses você teve contato com ou participou de alguma atividade de prevenção de HIV, conduzida por profissional de saúde?

Sim (1) Não (2)

Qual(is)?

$2^{\mathrm{F}}$. Você já foi a um Centro de Testagem e Aconselhamento (CTA)?

Sim (1) Não (2)

$3^{\mathrm{F}}$. Você fez alguma vez o teste de HIVIAIDS?

Sim (1) Não (2)

$4 \mathrm{~F}$. Você poderia me dizer o resultado?

$\begin{array}{ll}\text { Positivo } & \text { (1) } \\ \text { Negativo } & \text { (2) } \\ \text { Não sei } & \text { (3) } \\ \text { Não quero dizer } & \text { (4) }\end{array}$

$5^{\mathrm{F}}$. Considerando suas praticas sexuais, qual seu percentual de chance de contrair HIV nos próximos 12 meses?

Já estou infectado (1)

$0 \%$ 


\section{Bloco G - Percepções sobre o tema sexo e drogas}

$1^{G}$. Qual sua opinião sobre o uso de drogas.

$2^{G}$. Como você vê o uso de drogas dentro da "balada".

$3^{G}$. Como você percebe o uso de drogas e fazer sexo.

$4^{G}$. Você sabe se uso de drogas interfere na ereção? Isso acontece com você?

$5^{G}$. Fazer sexo sem ereção é uma prática comum? E para você é comum?

$6^{G}$. Quando ocorre o uso de drogas se usa o preservativo quando se faz sexo? Isso se aplica a você?

$7^{G}$. Além do preservativo você conhece outro método para prevenção? 


\section{Referências bibliográficas}

ABEP - Associação Brasileira de Empresas de Pesquisa- Dados com base no Levantamento Sócio Econômico 2011 - IBOPE 2012.

Almeida SP, Silva MTA: Ecstasy (MDMA): effects and patterns of use reported by users in São Paulo. Rev Bras Psiquiatr; 25 (1): 11-7. 2003.

Almeida SP; Silva MTA. Histórico, efeitos e mecanismo de ação do êxtase (3-4 metilenodioximetanfetamina): revisão da literatura.Rev Panam Salud Publica/Pan Am J Public Health 8(6), (393- 402). 2000.

Andrade SMO, Tamaki EM, Vinha JM, Pompilio MA, Prieto CW, Barros LM, Lima LB, Chaguri MC, Pompilio SAL. Vulnerabilidade de homens que fazem sexo com homens no contexto da AIDS. Cad. Saúde Pública, Rio de Janeiro, 23(2):479-482, fev, 2007.

Antunes MC. Territórios de Vulnerabilidade ao HIV: Homossexualidades masculinas em São Paulo. São Paulo. Instituto de Psicologia da Universidade de São Paulo. 2005. 
Ayres JRCM, França Junior I, Calazans G, Salletti H. Vulnerabilidade e prevenção em tempos de Aids. In: Barbosa R, Parker R, organizadores. Sexualidade pelo avesso: direitos, identidades e poder. Rio de Janeiro: Relume Dumará; p. 50-71. 1999.

Ayres JRCM. et al. $\mathbf{O}$ conceito de vulnerabilidade e as práticas de Saúde: novas perspectivas e desafios. In: CZERESNIA, D. (Org.). Promoção da saúde: conceitos, reflexões, tendência. Rio de Janeiro, Fiocruz,. p. 117-139. 2003.

Ayres, JRCM. Práticas educativas e prevenção de HIVIAids: lições aprendidas e desafios atuais. Comunic, Saúde, Educ, v.6, n.11, p.11-24, 2002.

Barbosa Júnior A, Szwarcwald CL, Pascom ARP, Souza Júnior PB: Tendências da epidemia de AIDS entre subgrupos sob maior risco no Brasil, 1980-2004. Cad. Saúde Pública, Rio de Janeiro, 25(4): 727-737, abr, 2009.

Bardin Laurence. Análise de Conteúdo. $3^{a}$ reimp. Da $1^{a}$ edição de 2011.São Pulo. Edições 70; 2011. 
Battisti MC, Noto AR, Nappo S, Carlini EA: A profile of ecstasy (MDMA) use in São Paulo, Brazil: an ethnographic study. Journal of Psychoactive Drugs, March, Volume 38(1). 2006.

Brasil, Ministério da Saúde. Secretaria Executiva. Secretaria de Atenção a Saúde. Coordenação Nacional DST/AIDS. A Política do Ministério da Saúde para Atenção Integral a Usuários de Álcool e Outras Drogas $1^{\text {a }}$ ed. Brasília:, 2003

, Observatório Brasileiro de Informações sobre Drogas, [citado 01 de Novembro de 2011] Disponível em: www.obid.senad.gov.br , Programa Nacional de DST e AIDS: UNGASS- Resposta brasileira 2005-2007 Relatório de progresso do País, 2008. . Ministério da Saúde. Secretaria de Vigilância em Saúde. Departamento de DST, Aids e Hepatites Virais. Pesquisa de conhecimento, atitudes e práticas na população brasileira Ministério da Saúde. Secretaria de Vigilância em Saúde. Departamento de DST, Aids e Hepatites Virais. Brasília: Ministério da Saúde, 2011. 
. Ministério da Saúde. Álcool e redução de danos: uma abordagem inovadora para países em transição 1. Ed. Brasília. 2004.

Brignol S, Dourado I. Inquérito sociocomportamental sobre as práticas sexuais desprotegidas entre homens que fazem sexo com homens usuários da Internet.. Revista Brasileira de Epidemiologia 14(3): 423-34 4. 2011.

Carvalho HB ; Seibel SD ; Burattini MN ; Massad E ; Reingold A . Vulnerabilidade às infecções pelo HIV, hepatites $\mathrm{B}$ e C e sífilis entre adolescentes infratores institucionalizados na cidade de São Paulo, Brasil. DST. Jornal Brasileiro de Doenças Sexualmente Transmissíveis, Rio de Janeiro, v. 15, n. 3, p. 41-45, 2003.

Carvalho HB, Mesquita F, Massad E, Bueno RC, Lopes GT, Ruiz MA, Burattini MN. HIV and infections of similar transmission patterns in a drug injectors community of Santos, Brazil. Jornal of Acquired Immune Deficiency Syndrome and Human Retrovirology. May 1;12(1):84-92. 1996. 
Catania JA, Kegeles SM, Coates TK. Towards an Understanding of Risk Behavior: an AIDS Risk Reduction Model (ARRM). Health Education Quartely, 17(1):53-72. 1990.

Centro Brasileiro de Informação sobre Drogas Psicotrópicas: UNIFESP - Universidade Federal de São Paulo e Secretaria Nacional Antidrogas: Levantamento domiciliar sobre o uso de drogas psicotrópicas no Brasil: estudo envolvendo as 107 maiores cidades do país : 2001. Câmara Brasileira do Livro, São Paulo, Brasil. 2002.

II Levantamento domiciliar sobre o uso de drogas psicotrópicas no Brasil: estudo envolvendo as 108 maiores cidades do país : 2005. Câmara Brasileira do Livro, São Paulo, Brasil. 2006.

V Levantamento Nacional sobre o Consumo de Drogas Psicotrópicas entre Estudantes do Ensino Fundamental e Médio da Rede Pública de Ensino nas 27 Capitais Brasileiras. São Paulo, 2004.

Clatts MC, Goldsamt $\mathrm{LA}$ and $\mathrm{Yi} \mathrm{H}$ : An emerging HIV risk environment: a preliminary epidemiological profile af an msm POZ Party in New York. Sex Transm Infect. 81: 373-376.a. 2005. 
Clatts MC, Goldsamt LA and Yi H: Drug and sexual risk in four who have sex with men populations: evidence for a sustained HIV epidemic in New York City. J Urban Health. March; 82 (1 Suppl 1): i9-17.b. 2005.

Coleman E, Horvath KJ, Miner M, Ross MW, Oakes M, Rosser BRS. Compulsive Sexual Behavior and Risk for Unsafe Sex Among Internet Using Men Who Have Sex with Men.. Arch Sex Behav. 39:1045-1053. 2010.

Domanico A. "CRAQUEIROS E CRACADOS: BEM VINDO AO MUNDO DOS NÓIAS!" - Estudo sobre a implementação de estratégias de redução de danos para usuários de crack nos cinco projetos-piloto do Brasil. Salvador, Universidade Federal da Bahia. Faculdade de Filosofia e Ciências Humanas, 2006.

Duarte DF. Uma breve história do Ópio e dos Opióides. Revista Brasileira de Anestesiologia. Vol.55, n¹, 135-146. 2005.

Dumchev KV, Soldyshev R, Qian HZ, Zezyulin OO, Chandler SD, Slobodyanyuk P, Moroz L, Schumacher JE. HIV and hepatitis C virus infections among hanka injection drug users in central 
Ukraine: a cross-sectional survey. Harm Reduct J. Aug 23;6:23. 2009.

Feng Y, Wu Z, Detels R, Qin G, Liu L, Wang X, Wang J, Zhang L. HIVISTD prevalence among MSM in Chengdu, China and associated risk factors for HIV infection. J Acquir Immune Defic Syndr. Feb;53 Suppl 1:S74-80. 2010.

Fletcher H, Fletcher SW. Epidemiologia Clínica. 4ª edição. Porto Alegre: Editora Artmed; 2006.

Gondim RC, Kerr LRFS, Werneck GL, Macena RHM, Pontes MK, Kendall C. Risck sexual practices among men who have sex with men in Northeast Brazil: results from four sequential surveys. Cad. Saúde Pública, Rio de Janeiro, 25(6):1390-1398, jun, 2009.

Gondim RC. Comportamento sexual e uso de álcool e drogas entre homens que fazem sexo com homens no ceará: tendências e práticas de risco para as DSTIAIDS. Rio de Janeiro. 2006. 
Halkitis PN, Palamar JJ, Mukherjee PP. Poly-club-drug use among gay and bisexual men: A longitudinal analysis.. Drug and Alcohol Dependence. № 89. 153-1.60. 2007.

Harawa NT, Williams JK, Ramamurthi HC, Manago C, Avina S, Jones M: Sexual Behavior, Sexual identy, and substance abuse among low-income bisexual and non-gay-identifying african american men who have sex with men. Arch sex Bahav. October; 37(5):784-762. 2008.

Henrique, I. F.S. Micheli, D. Lacerda, R.B. Lacerda, L.V. Formigoni, M.L.O.S. Validação da versão brasileira do Teste de Triagem de envolvimento com Álcool, Cigarro e Outras Substâncias (ASSIST) Rev Assoc Med Bras; 50(2): 199-206. 2004.

Humeniuk, R. Ali, R Validation of the Alcohol, Smoking and Substance Involvement Screening Test (ASSIST) and pilot brief intervention [electronic resource]: a technical report of phase II findings of the WHO ASSIST Project. WHO 2006

Kubicek K, McDavitt B, Carpineto J, Weiss G, Iverson EF, Kipke MD: Making informed decisions: how attitudes and perceptions affect the use of crystal, cocaine an ecstasy 
among young men who have sex with men. J Drug Issues.; 37(3): 643-674. 2007.

Laranjeira, Ronaldo et al. I Levantamento Nacional sobre os padrões de consumo de álcool na população brasileira. Brasília. Secretaria Nacional Antidrogas, 2007.

Larmarange J, Wabe AS, Diop AK, Diop O, Gueye K, Marra A, Desgrées du Loû. A. Men Who have sex men (MSM) and factors associated with not using a condom intercourse with man and with woman in Senegal. PLoS One.. Volume 5. Issue 10. e13189 2010.

Malta M, Magnanini MMF, Mello MB, Pascom ARP, Linhares $Y$ and Bastos FI: HIV prevalence among female sex workers, drug user and men who have sex with men in Brazil: A Systematic Review and Meta-analysis. BMC Public Health, 10:317. 2010.

Mendoza-Pérez JC, Ortiz-Hernández L: Factores asociados con el uso inconsistente de condón em hombres que tienen sexo con hombres de Ciudad Juárez. Rev. Salud Púplica. 11(5): 700712, 2009. 
Nguyen TA, Nguyen HT, Le GT, Detels R: Prevalence and risk factors associated with HIV infection among men having sex with men in Ho Chi Minh City, Vietnam. AIDS Behav. May; 12(3): 476-482. 2008.

Parsons, J. T.; Kutnick, A. H.; Halkitis, P. N.; Punzalan, J. C.; Carbonari,Jj. P. Sexual risk behaviors and substance use among alcohol abusing HIV-positive men who have sex with men. Journal of Psychoactive Drugs, v. 37, p. 27-36, 2005.

Patterson, T. L.; Semple, S. J.; Zians, J. K.; Strathdee, S.A. Methamphetamineusing HIV-positive men who have sex with men: correlates of polydrug use. J.Urban.Health,v. 82, p. i120i126, 2005.

Sánchez, AIM; Bertolozzi, MR. Pode o conceito de vulnerabilidade apoiar a construção do conhecimento em Saúde Coletiva? Ciênc. saúde coletiva vol.12 no.2 Rio de Janeiro Mar./Apr. 2007.

Santos AO, Paiva V. Vulnerabilidade ao HIV: turismo e uso de álcool e outras drogas. Rev Saúde Pública;41(Supl. 2 ):80-6 2007. 
Schwarcz S, Scheer S, McFarland W, Katz M, Valleroy L, Chen S, Catania J: Prevalence of HIV infection and predictors of hightransmission sexual risk behaviors among men who have sex with men. Sex Transm Infect; 82: 131-134. 2006.

Spiassi AL. Conversas com o movimento social negro sobre vulnerabilidades em relação às DST/Aids. São Paulo. Faculdade de Medicina da Universidade de São Paulo. 2011.

Thomas B, Mimiaga MJ, Mayer KH, Johnson CV, Menon S, Chandrasekaran V, Murugesan P, Swaminathan S, Safren SA. HIV Prevention Interventions in Chennai, India: Are Men Who Have Sex with Men Being Reached? AIDS PATIENT CARE and STDs, , Vol 23, n. 11. 2009.

Tobin KE, Latkin CA: An examination of social network characteristics of drug using men who have sex with men (MSM). Sex Transm Infect. November; 84(6): 420-424. 2008.

Touko A, Mboua CP, Tohmuntain PM, Perrot AB. Sexual vulnerability and HIV seroprevalence among the deaf and hearing impaired in Cameroon. Journal of the International AIDS Society, 13:5. 2010. 
UNODC Relatório Mundial Sobre Drogas WRD 2010. [Release de: Escritório das Nações Unidas sobre Drogas e Crime]. 2010 Informe Mundial sobre las Drogas 2012, Viena, 2012, van der Meer ZS, Oliveira LG, Ribeiro LA, Nappo SA. The role of information as a preventive measure to the drug use among young people at risk. Ciência \& Saúde Coletiva, 15(3):699-708, 2010.

van Kesteren NMC, Hospers HJ, Kok G. Sexual risk behavior among HIV-positive men who have sex with men: A literature review. Patient Education and Counseling. n65. 5-20. 2007. 